\title{
Thermal Converters as AC-DC Transfer Standards for Current and Voltage Measurements at Audio Frequencies
}

\author{
Francis L. Hermach
}

\begin{abstract}
Thermal converters and associated equipment that are used as ac-de transfer standards at the National Bureau of Standards for the precise measurement of current and voltage at power and audio frequencies are described. The standards and the equipment are primarily used to standardize a-c ammeters and voltmeters submitted to the Bureau for certification. The ac-de transfer may be made with these thermal converters at currents from 1 milliampere to 50 amperes, voltages of 0.2 to 750 volts, with an accuracy of 0.01 percent at frequencies from 25 to 20,000 cycles per second.

The special tests to insure the required accuracy of the transfer standards are described, and the results are presented. A number of factors that limit the transfer accuracy of thermal converters have been discovered, and the results of special tests and theoretical work to evaluate these factors are discussed. The solutions, by an approximation method, of certain pertinent nonlinear differential equations governing the heating of a conductor by an electric current are given.
\end{abstract}

\section{Introduction}

The increasing use of electric energy for aircraft, induction furnaces, and induction heating, and the greater accuracy required in measurements in electronics, have led to increasing demands for the accurate standardization of ammeters and voltmeters at frequencies extending upward from power frequencies through the entire audio-frequency range. To meet these demands, special instruments have been developed at the National Bureau of Standards for the measurement of current and voltage over rather wide ranges. They make use of thermal converters ${ }^{1}$ (often called thermoelements) like those incorporated in ordinary thermocouple instruments, but differ in the manner of reading and use. They may be used either directly to measure the ac-de differences of ammeters and voltmeters, or with a suitable potentiometer and accessories to measure alternating currents and voltages. They were designed and are used primarily for testing electric instruments, at currents from $1 \mathrm{ma}$ to $50 \mathrm{amp}$ and voltages from 0.2 to $750 \mathrm{v}$, with an accuracy of 0.01 percent at frequencies from 25 to $20,000 \mathrm{c} / \mathrm{s}$.

\section{Transfer Principle}

The basic electrical units are defined in terms of a concordant system of mechanical units and are realized by absolute electrical measurements carried out at national standardizing laboratories to fix the value of groups of standard cells and resistors. These standards are used in conjunction with a potentiometer to make measurements of direct voltage, current, and power. It has been known for a long time, but not sufficiently realized, that the measurement of the corresponding alternating-

Proposed AIEE definition 30.89.040: A thermal converter is a device that consists of one or more thermojunctions in thermal contact with an electric heater or integral therewith, so that the electromotive force developed at its output terminals by thermoelectric action gives a measure of the input current in its heater. current quantities depends fundamentally on certain standard types of electric transfer instruments that ideally have the same response on direct and alternating current. If the instruments are calibrated on direct current at the time of each use and if the precision of reading is suitably increased, long-time stability, freedom from drift, small temperature influence, low losses, and other normally desirable characteristics become of secondary importance, and the instruments may be primarily designed and constructed to have the best possible frequency characteristic. For difference measurements such instruments need not have long scales in the ordinary sense, but rather may be designed for increased precision of reading by methods that would not be applicable to instruments intended for general service.

Special electrodynamic transfer instruments have long been used at the Bureau for accurate a-c measurements. These transfer standards are used largely to standardize (test) other instruments submitted to the Bureau for certification. There are two distinct types of such tests. For the "straight a-c test", the instrument under test and a transfer standard are connected to measure the same alternating electrical quantity (current, voltage, or power), which is adjusted to produce the desired deflection of the test instrument. The response of the standard instrument is observed, then the standard is transferred to direct current. The direct quantity is adjusted to give the same response of the standard and is then measured with a suitable potentiometer and accessories. For the so-called "ac-dc difference test", both instruments are connected to measure the same quantity first on alternating and then on direct current, which is in each case adjusted to give the same deflection of the test instrument. From the averaged difference in the response of the transfer standard, the ac-dc difference of the test instrument is computed. The second type of test can be made with somewhat higher accuracy than the first, and in conjunction 
with a test on direct current gives more information about the performance of the test instrument. Because the ac-dc difference of an instrument depends upon geometrical factors that are relatively permanent, subsequent tests for checking the constancy of calibration need generally be made only on direct current. Occasionally transfer tests are made by using a selected low frequency (such as $60 \mathrm{c} / \mathrm{s}$ ) as the reference in place of direct current.

An example of the accuracy with which such tests are made, laboratory standard instruments, with scales 12 in. long, are regularly standardized and certified at the Bureau to 0.05 of a scale division. For a 150-division instrument this requires an accuracy of measurement of 0.03 percent or better.

\section{Development and Description of Electro- thermic Transfer Standards}

\subsection{Choice of Standards}

Several types of instruments were considered in choosing transfer standards to cover the full audiofrequency range. Electrodynamic instruments have been highly developed $[1,2,3]^{2}$ at the Bureau for measurements at the commercially important power frequencies and can be used with proper corrections, up to about $2,000 \mathrm{c} / \mathrm{s}$. However, unavoidable inductance and stray capacitance errors limit their useful frequency range and present little hope for the desired extension. Electrostatic instruments have been carefully studied $[4,5]$ at the National Physical Laboratory. They are useful over wide frequency ranges, but because of their low-torque-weight ratio at low voltage are not readily adaptable for either the low voltage or the current ranges desired in this application. Electrothermic instruments, which use an effect produced by the heating of a conductor carrying a current to be measured, seemed more promising. Of the several kinds, thermocouple instruments, in which the temperature rise of the conductor (heater) is measured by a thermocouple, seemed most feasible. Straight-wire heaters allow a wide frequency range, and the thermocouple measurements permit high precision of reading. The usual disadvantages of poor stability and large temperature influence are not important in their use as transfer instruments, and their low overload capacity is not a serious limitation in careful laboratory work. Fortunately, good thermal converters are commercially available. They have been used for measurements at frequencies up to about $65 \mathrm{Mc}$, with a d-c millivoltmeter as the indicator, and are generally considered in the $1 / 2-$ to 2 -percent accuracy classes. So far as is known, they have not been previously studied for use as transfer instruments at the frequencies and the accuracies needed in this application.

For these reasons, commercial thermal converters were selected for study to determine their value as ac-dc standards in a wide-range audio-frequency

${ }_{2}$ Figures in brackets indicate the literature references at the end of this paper. transfer voltmeter. A careful experimental and theoretical study of their performance led to the purchase of additional commercial thermal converters of suitable ranges and the design and construction of equipment for using them as transfer standards for voltage and current.

\subsection{Description of Transfer Standards}

Each thermal converter purchased in the milliampere ranges is of the vacuum type, mounted in an evacuated glass bulb with supports of copper wire embedded in the glass. The conductor, heated by the current to be measured, is a short straight wire generally less than $1 / 2 \mathrm{~cm}$ long and often less than 0.001 in. in diameter. The heater alloy and dimensions are chosen to give a temperature rise of about $200^{\circ} \mathrm{C}$ at the center where the hot junction of the thermocouple is fastened by a ceramic bead. This bead provides electrical but not thermal insulation between the heater and thermocouple circuits, with a coupling capacitance less than $1 \mu \mu \mathrm{f}$ and an insulation resistance greater than 50 megohms at $25^{\circ} \mathrm{C}$.

Because high current sensitivity is not required, the thermal converters in the 1 - to 50 -amp ranges are not evacuated. The hot junction of the thermocouple is welded directly to the midpoint of a thinwalled tubular heater. These thermal converters are temperature compensated [6].

For current measurements, thermal converters in the series $1,2,5,10$, etc., with rated output electromotive forces of $10 \mathrm{mv}$ were purchased, with ranges from 1 ma to 50 amp. Thermal converters of 7.5and 30 -ma ratings, with appropriate series resistors, are used for voltage measurements. Figures 1 and 2 show some of the thermal converters and the model $A$ and model B voltmeter elements. It should be emphasized that the caption NBS on the nameplate sbown in figure 2 signifies only that the equipment was assembled for use at the National Bureau of Standards. All the thermal converters were purchased commercially, as were the components of the voltmeters. It should also be emphasized that the thermal converters shown in these figures are the transfer elements only. An indicator (to be discussed in the next section) is necessary for all measurements, and a potentiometer and accessories are also necessary, except for transfer tests of other instruments.

The model A voltmeter was developed as a prototype instrument to meet an immediate need for voltage measurements. It consists of a 30-ma thermal converter connected with its heater in series with a commercial decade resistance box, modified to have two 1,000-ohm-per-step decades, and a 100-, a 10- and a 1-ohm-per-step decade, all in series. As shown in figure 3, one end of the heater of the thermal converter is connected to the low-side terminal of the box, with the shield of the box connected to the other end of the heater and to the shield of the coaxial cable connecting the instrument to the circuit. The center lead of this cable is connected directly to the high-side terminal of the box. 


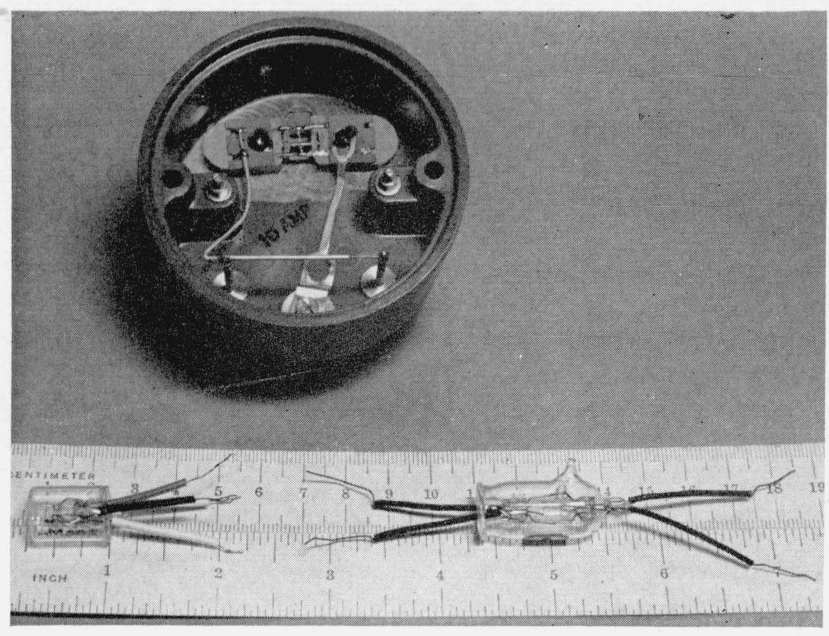

Figure 1. Typical thermal converters.

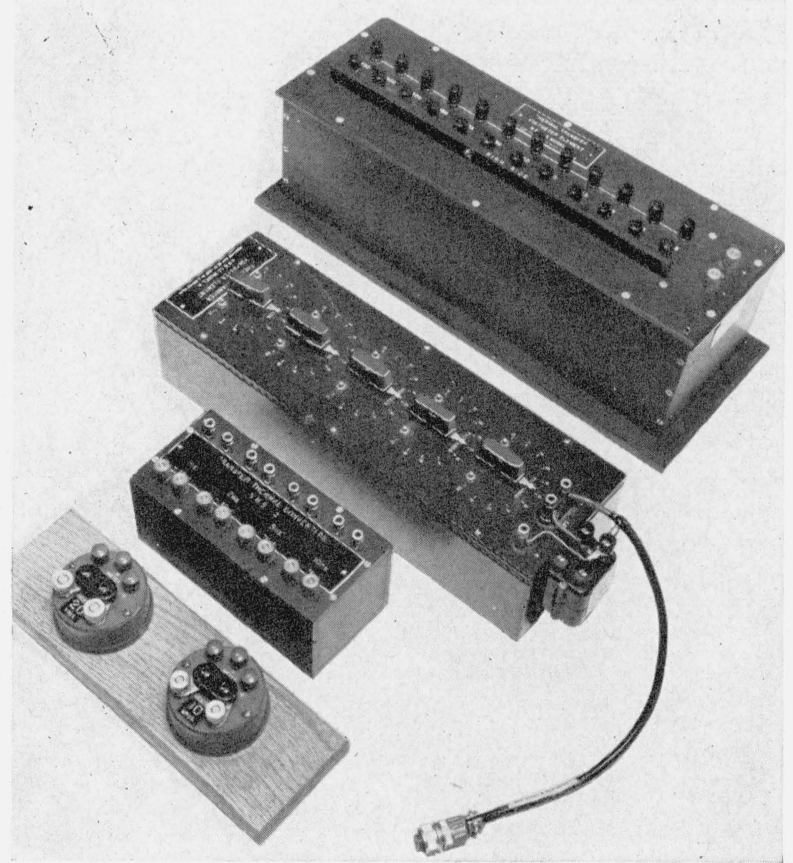

Figure 2. Mounted thermal converters and the model $A$ and model $B$ voltmeter elements.

Like the electrodynamic transfer standards used at lower frequencies, the series resistor is adjusted in use to give the same nominal current level for each measured voltage. This was chosen at $20 \mathrm{ma}$, resulting in a voltmeter having a constant $50 \mathrm{ohms} / \mathrm{v}$ and an upper range of $400 \mathrm{v}$. The model A voltmeter, described in some detail in an earlier paper [7] is now no longer used for routine measurements.

For the model B voltmeter, a built-in 7.5-ma thermal converter was used, with a fixed resistor having taps to give voltage ranges of $1.5,3,6,7.5$, $15,30,60,75,150,300,600$, and $750 \mathrm{v}$. The resistance cards for this instrument were purchased commercially, and the cards and thermal converter were mounted in a suitable shielded box with the shield connected to the low-side terminal of the instrument, as shown in figure 3. For both instruments the effects of capacitance currents and of the selfinductance of the resistors were carefully considered; the limiting factors are discussed in another section of this paper.

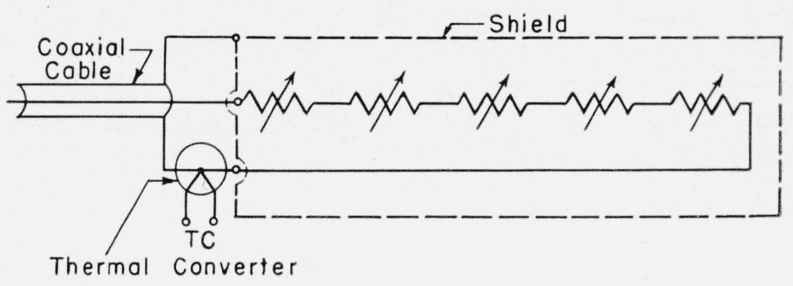

A

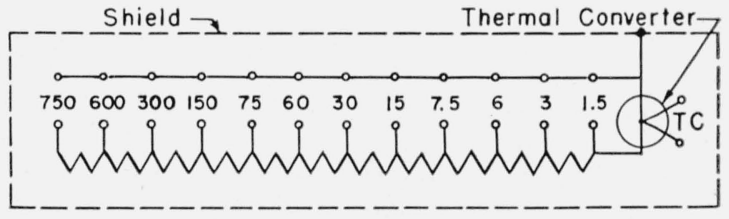

B

Figure 3. Circuit diagrams of the model $A$ and model $B$ voltmeter elements.

A, Model A voltmeter element; B, model B voltmeter element,

\subsection{Indicator}

Because of its convenience and portability, a millivoltmeter is generally used for measuring the emf in the usual thermocouple instrument. The precision of reading of the usual millivoltmeter is of course far too low for this application. For increased accuracy a potentiometer can be used to measure the thermocouple emf. However, if the thermal converter is used only as a transfer standard, the emf need not be measured in a "straight a-c" test; and in ac-dc difference tests it is only the small change in emf between the a-c and d-c settings that is significant. The change and the full emf with which it is compared need be measured with relatively low accuracy, provided the change is referred to a highly stable base value. Thus high sensitivity and high stability but only moderate accuracy in the measurement of emf are required of the indicator. For these requirements, a Lindeck potentiometer for providing the base value, used in conjunction with a suitable galvanometer, the deflection of which indicates the change, forms the ideal indicator. In a Lindeck potentiometer, based on Poggendorf's second principle [8], the emf to be measured is balanced by an adjustment of the current through a fixed resistor. At balance the voltage drop across the resistor, which is the product of the potentiometer current and the resistance, is equal to the measured emf. The current is ordinarily measured with a milliam- 
meter, which generally sets the limit on the accuracy obtainable with this form of potentiometer.

Such a potentiometer has been incorporated in a panel constructed for the audio-frequency testing. It was designed to have adequate stability, freedom from changing extraneous electromotive force and the required ranges, with sufficient precision of reading. Its circuit is shown in the central portion of figure 4 . The resistor, $R$, is made of manganin, and a special thermofree key [8] and copper binding posts are used in the electrothermally sensitive emf circuit. The components are mounted in the central part of the panel, as shown in figure 5, and are enclosed by a

\subsection{Use of Instruments}

These transfer standards are used almost solely for standardizing other a-c instruments. The necessary switching and control circuits for such tests have been incorporated in the panel shown in figure 5. In addition to these circuits and the Lindeck potentiometer, the panel contains the impedance-matching transformers for the high-voltage circuits used in testing voltmeters and the high-current circuits used in testing ammeters. The present transformers provide ranges up to $50 \mathrm{amp}$ and $800 \mathrm{v}$, with a nominal input voltage of $150 \mathrm{v}$ and a power level up to $100 \mathrm{w}$.

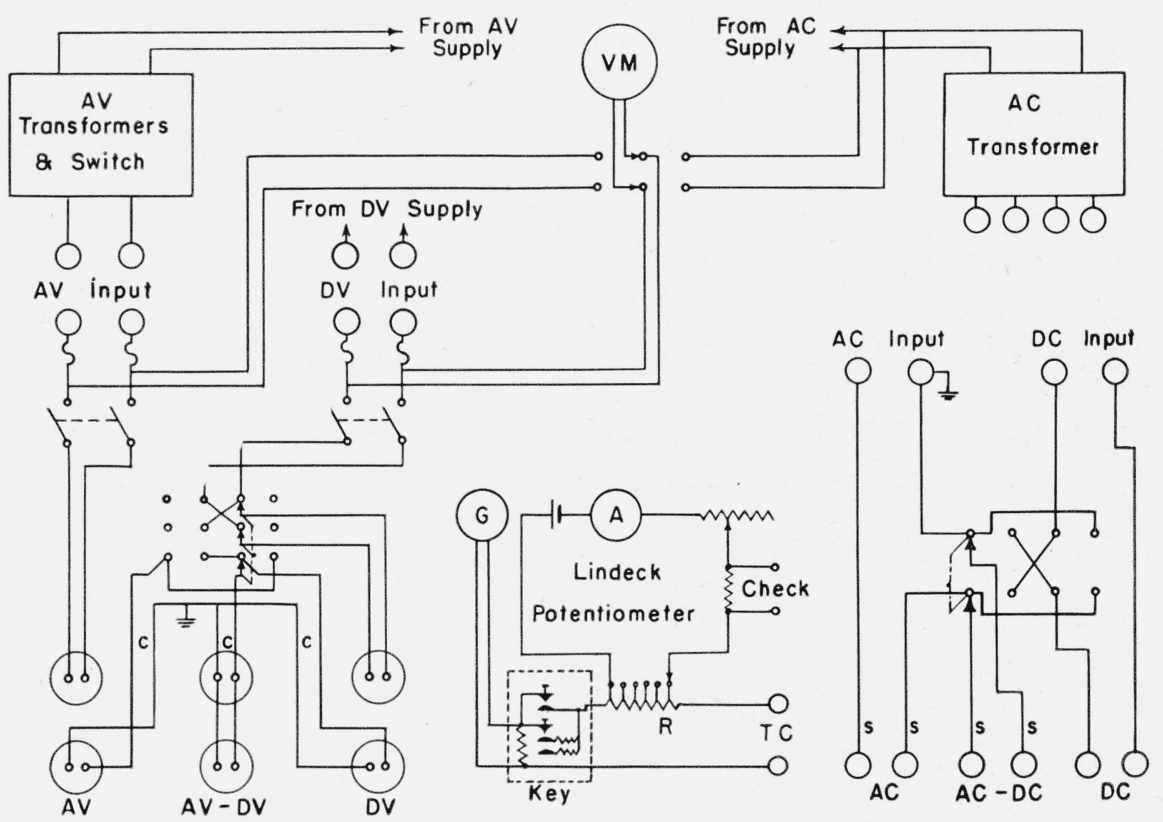

Figure 4. Schematic diagram of circuits used for testing instruments.

C signifies coaxial lead with shield grounded; S signifies shielded lead with shield grounded.

grounded metal shield. No other thermal precautions were found necessary. A reflecting wallmounted galvanometer is used, with a voltage sensitivity (in the circuit) of $1 \mathrm{~mm} / \mu \mathrm{v}$. A No. 6 dry cell supplies the potentiometer current, which is adjustable from 0.2 to $1.2 \mathrm{ma}$. At these current levels, repeated tests have shown that the steady drift in the voltage across the four terminal resistor is less than 0.02 percent per hour, and that superposed fluctuations are much less than 0.01 percent. The fourterminal manganin resistor has taps at $0.1,0.5,2.5$, 5,10 , and 25 ohms, giving milivolt ranges, at a current of $1 \mathrm{ma}$, of these same numerical values. The lowest range is used in transfer tests as a quick check of the potentiometer. With the thermocouple of the thermal converter connected to the "TC" posts of the potentiometer, but with no current through its heater, a galvanometer deflection of 10.0 $\mathrm{cm}$ to the left on the scale with the Lindeck set for 0.1 mv serves as a valuable partial check of the required accuracy and correctness of the Lindeck circuit.
Motor-generator sets and voltage stabilizers are available for tests at $60 \mathrm{c} / \mathrm{s}$ and audio-frequency oscillators and power amplifiers for tests at other frequencies. Batteries, controlled by suitable adjustable resistance voltage dividers and series resistors, are used for the necessary direct-current sources. The potentiometer, standard cells, volt boxes, and resistors are those normally used for instrument testing and are periodically standardized to insure a continued accuracy of considerably better than 0.01 percent.

A schematic diagram of the major circuits and equipment on this panel is shown in figure 4 . For an a-c test of an ammeter, the transfer thermoelement is connected to the AC-DC binding posts and its thermocouple to the TC posts on the panel. The test instrument is connected to the $\mathrm{AC}$ posts, and a suitable four-terminal standard resistor is connected to the DC posts for use in measuring the d-c current by means of a potentiometer. For low currents at the higher audio frequencies, shielded leads with the 
shields grounded are used to minimize errors due to stray capacitance currents. The alternating current is adjusted for the desired deflection of the test instrument, and the Lindeck potentiometer is adjusted for an "on-scale" deflection of the galvanometer. The standard instrument is then switched to direct current, which is adjusted to give the same galvanometer deflection and is then measured with the external potentiometer. The direct current through the heater of the thermoelement is then reversed and the d-c measurement repeated. ${ }^{3}$

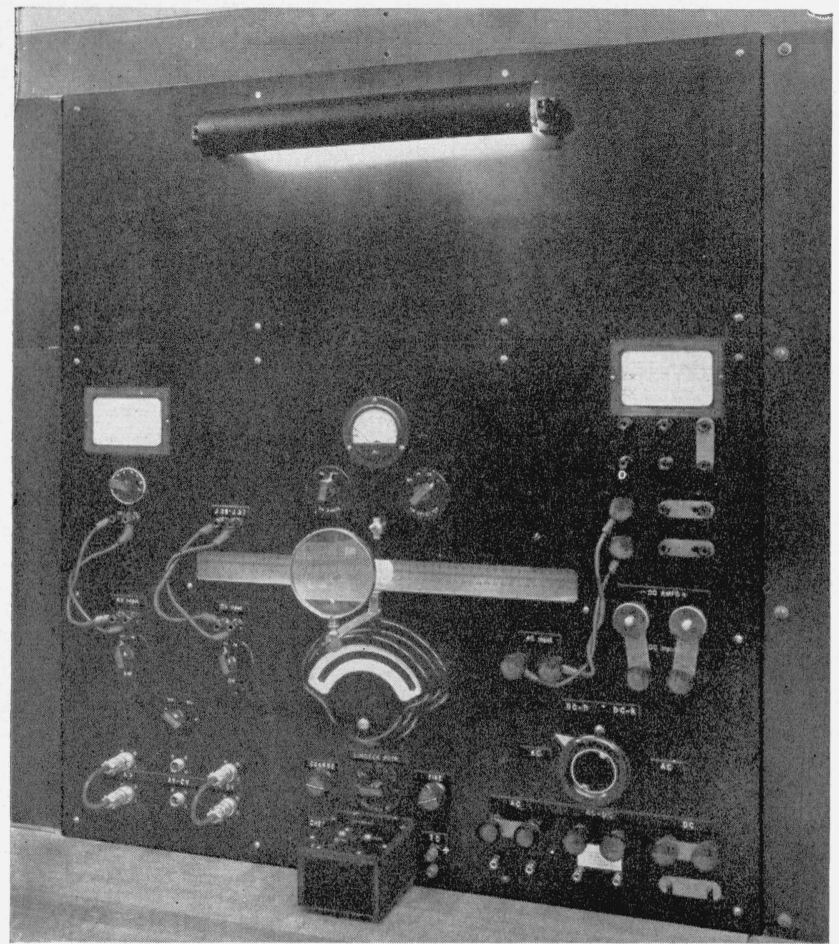

FIGURE 5. Instrument testing panel, including Lindeck element.

For an a $\cdots$ c test of a voltmeter, a similar procedure is used. The transfer standard is connected to the AV-DV receptacle on the panel with a coaxial lead, with due care to connect its thermal converter to the grounded shield of this lead, and the thermocouple is connected to the TC posts on the panel. The test instrument is connected to the circuit with a special twin lead consisting of two coaxial lines permanently paralleled at the instrument and connecting to the two AV receptacles on the panel. Similar leads of the same length are used to connect the high side of a volt box for use with the external potentiometer to measure the direct voltage, to the two DV receptacles. The use of these leads eliminates the effect of any stray magnetic field or lead resistance on the measurements.

This simple procedure is reliable only if the drift of the response of the standard instrument is negligibly small in the time taken for a series of such

3 Such reversed d-c readings are common practice for highest accuracy with all types of ac-de instruments. readings. This is fortunately true for each of the thermal converters used. After an initial warm-up period of a minute or so, the maximum observed drift under those laboratory conditions of any of the thermal converters tested was less than 0.5 percent per hour, and the average less than 0.05 percent per hour. If it were necessary, the effect of significant drift could be practically eliminated by using a deflection method as outlined for transfer tests, calibrating the standard instrument on direct current at the nominally correct current or voltage before and after each a-c setting.

For ac-de difference or transfer tests, which are more frequent and usually more important than straight a-c tests, the test and standard instruments are connected in series to the AC-DC posts ${ }^{4}$ in the case of ammeters, or in parallel with suitable coaxial leads to the $A V-D V$ receptacles in the case of voltmeters. Suitable short leads are used to connect the two AV receptacles together and to connect the two DV receptacles together. The current or voltage is adjusted for the desired deflection of the test instrument, and the Lindeck potentiometer is adjusted for a deflection near the null position at the center of the galvanometer scale. The two instruments are then in quick succession connected to alternating, direct, reversed direct, and then alternating current. The current is adjusted to give the same deflection of the test instrument in each case. The resulting deflections of the galvanometer of the Lindeck potentiometer are observed with the potentiometer controls undisturbed. This procedure practically eliminates any effect of drift in either instrument, and errors in repeating the settings of the instrument under test can be made very small by using a lowpower microscope and setting the image of the instrument pointer in coincidence with a cross-hair in the eyepiece. The control circuits have been arranged to facilitate switching, and with two observers the procedure is rapid even with moderately fluctuating voltages as only one of the two instruments is set to a given deflection.

From the average of the deflections on alternating and on direct current, the ac-de difference of the test instrument is readily computed by a simple formula. ${ }^{5}$

\section{Evaluation of Transfer Performance}

The ac-dc difference of each transfer standard must be known to the full accuracy desired in the measurements to be made. As, in a sense, there are no absolute transfer standards, such an evaluation essentially consists of four steps.

1. Choice of a type of instrument that theory indicates is suitable over the desired ranges.

2. Study of all known effects that can cause such an instrument to depart from this ideal.

3. Construction and use of an instrument in such a way that these effects, by computation or direct tests of the separate components, are negligible or known.

${ }^{4}$ One terminal of the heater is connected to the post that is grounded on alternating current.

5 The formulas used in computing the results of the a-c and transfer tests are developed in appendix 1 . 
4. Comparison of actual transfer performance of the standard with that of some other instru-. ment, preferably of a quite different type, whose performance has also been evaluated.

The evaluation of these electrothermic transfer standards was considered of primary importance because of the high order of accuracy demanded in this application. The unique facilities of the Bureau made this quite feasible, particularly for step 4, which is necessary to guard against errors from unsuspected causes. Prototype instruments such as these, in which previously available ranges are greatly extended, cannot be directly compared with other types of standards over their full range. The evaluation therefore consisted of the study, computations, and special tests of steps 2 and 3 during the design and construction of these instruments and their panel, the intercomparisons of thermal converters of adjacent current ranges in the series, the comparison at low frequencies of selected thermal converters with the electrodynamic transfer stand-. ards at the Bureau, and the comparison of these thermal converters with certain portable hot-wire and electrostatic instruments also available.

A thermal converter can be used as a transfer standard for alternating--current measurements over the range of frequencies for which the response char. acteristic, $E=f(I)$, is the same as with direct current, where $E$ is the output emf, and $I$ the current through the heater of the thermal converter. For a volt.. meter element consisting of a resistor in series with a thermal converter, the magnitude of the effective impedance $Z=V / I$ must also be equal to the effective resistance on direct current, where $V$ is the applied voltage. In addition to these two requirements for instrument testing, the fundamental principle that the standard and the instrument under test "see" exactly the same quantity must be carefully observed.

The response characteristic of the types of thermal converters used were believed to be suitable at frequencies far higher than those used in this applica- cation, and their direct-current and low-frequency responses were verified by special tests described in other sections. The effective impedance of each voltmeter element was approximately computed from inductance and capacitance data supplied by the manufacturer of the resistance cards, and was verified by special tests to be described later. The capacitance and resistance of the Lindeck potentiometer to ground were measured and found to be $1,600 \mu \mu \mathrm{f}$ and 10,000 megohms at an ambient relative humidity of 40 percent. Thus the computed stray currents are sufficiently small so that no appreciable fraction of the currents measured will be diverted through the thermocouple at audio frequencies when one end of the heater is grounded. The use of shielded leads where necessary, the avoidance of a ground between the test instrument and the standard in the current circuits, and the use of the special coaxial lines in the voltage circuits assure that the fundamental principle is observed even at the smallest current and voltage in the present ranges.

The comparison tests of step 4 were planned to give maximum possible assurance against errors due to unsuspected causes. Each comparison consisted of repeated careful transfer (ac-dc difference) tests, as described in section 3.4. The 1-, 2- and 5-amp thermal converters were compared with the NBS electrodynamic transfer ammeter at selected frequencies from 25 to $200 \mathrm{c} / \mathrm{s}$. The model A voltmeter was compared with the NBS suppressed-zero electrodynamic voltmeter at frequencies of 30 and $60 \mathrm{c} / \mathrm{s}$ and voltages from 20 to $240 \mathrm{v}$. Both of these electrodynamic instruments have been carefully studied $[1,2]$. They can be read with a precision of better than 0.005 percent. The results of these comparisons, corrected for the small known transfer errors of the electrodynamic instruments, are shown in table 1. They are estimated to be accurate to 0.005 percent or better. The results of these tests disclosed that the model A voltmeter and the electrodynamic voltmeter were in excellent agreement at these frequencies.

TABLE 1. Results of comparisons of thermal converters with other types of instruments

\begin{tabular}{|c|c|c|c|c|c|c|c|c|c|c|c|}
\hline \multirow{2}{*}{$\begin{array}{l}\text { Thermal converter } \\
\text { range }\end{array}$} & \multirow{2}{*}{ Other instrument } & \multirow{2}{*}{$\begin{array}{c}\text { Test } \\
\text { current } \\
\text { or } \\
\text { voltage }\end{array}$} & \multicolumn{9}{|c|}{ Comparative ac-dc difference } \\
\hline & & & $\begin{array}{l}25 \\
\mathrm{c} / \mathrm{s}\end{array}$ & $\begin{array}{l}30 \\
\mathrm{e} / \mathrm{s}\end{array}$ & $\begin{array}{l}60 \\
\mathrm{e} / \mathrm{s}\end{array}$ & $\begin{array}{l}100 \\
\mathrm{c} / \mathrm{s}\end{array}$ & $\begin{array}{l}200 \\
\mathrm{c} / \mathrm{s}\end{array}$ & $\begin{array}{c}1,000 \\
\mathrm{c} / \mathrm{s}\end{array}$ & $\begin{array}{c}10,000 \\
\mathrm{c} / \mathrm{s}\end{array}$ & $\begin{array}{c}15,000 \\
\mathrm{c} / \mathrm{s}\end{array}$ & $\begin{array}{l}20,000 \\
\mathrm{c} / \mathrm{s}\end{array}$ \\
\hline $\begin{array}{l}\quad a m p \\
1 \\
1 \\
1 \\
2 \\
2 \\
2 \\
5 \\
5\end{array}$ & 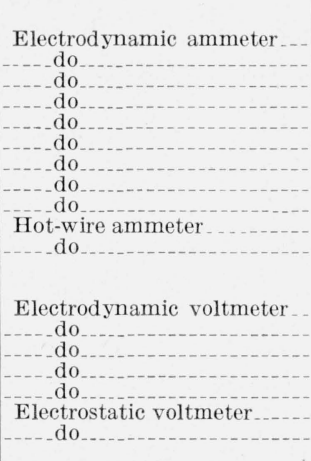 & $\begin{array}{c}a m p \\
0.4 \\
1 \\
1.2 \\
0.8 \\
2 \\
2.4 \\
4 \\
5 \\
6 \\
4 \\
5 \\
\\
v \\
\\
20 \\
50 \\
120 \\
150 \\
240 \\
150 \\
300\end{array}$ & $\begin{array}{r}\% \\
-0.001 \\
-.053 \\
-.067 \\
-.022 \\
-.115 \\
-.154 \\
-.004 \\
-.010 \\
-.011 \\
\end{array}$ & $\begin{array}{c}\% \\
\\
\\
\\
-0.002 \\
+.004 \\
+.004\end{array}$ & $\begin{array}{r}\% \\
+0.001 \\
-.013 \\
-.001 \\
-.025 \\
-.035 \\
-.006 \\
--.018 \\
\\
-.004 \\
-.005 \\
-.003 \\
-.002 \\
-\end{array}$ & $\begin{array}{r}\% \\
-0.001 \\
-.008 \\
-.008 \\
+.001 \\
-.009 \\
-.015 \\
-.005 \\
-.005 \\
-.008 \\
\end{array}$ & $\begin{array}{r}\% \\
-0.002 \\
-.001 \\
-.005 \\
+.001 \\
+.001 \\
-.002 \\
\end{array}$ & $\begin{array}{c}\% \\
\\
\\
-007 \\
\\
+.004 \\
-010\end{array}$ & $\begin{array}{c}\% \\
\\
-0.004 \\
\end{array}$ & $\begin{array}{c}\% \\
\\
\end{array}$ & $\begin{array}{c}\% \\
\\
-006 \\
\\
\\
\\
\\
+.009 \\
-002 \\
\end{array}$ \\
\hline
\end{tabular}


They disclosed significant disagreements between the ampere-range thermal converters and the electrodynamic ammeter, which were considered to be due to a low-frequency error in the 1- and 2-amp thermal converters and a small error independent of frequency in the 5-amp thermal converter.

The model A voltmeter was also compared with two new high-grade portable pivoted electrostatic voltmeters, having scales over $5 \mathrm{in}$. long, at selected frequencies from 30 to $20,000 \mathrm{c} / \mathrm{s}$. For increased precision a low-power microscope was focused on the pointer of the electrostatic instrument under test. This instrument was always set to the same deflection and was tapped lightly before each reading. Repeated sets of careful readings were taken at each frequency, and all tests were at the full-scale deflection of the electrostatic instrument. Because of these repeated readings and the favorable conditions, the averaged results are estimated to be accurate to 0.01 percent. The results, as shown in table 1 , verify the absence of capacitance errors in the thermal voltmeter. Direct comparisons at the higher frequencies could not be made at lower voltages, but calculations indicate that skin effect and the effect of inductance should be considerably less than 0.01 percent at $20,000 \mathrm{c} / \mathrm{s}$.

Similarly, the 5-amp thermal converter was compared with a high-quality portable 5-amp bot-wire ammeter at frequencies from 25 to $20,000 \mathrm{c} / \mathrm{s}$. The results, as shown in table 1 , indicate excellent agreement at frequencies of $1,000 \mathrm{c} / \mathrm{s}$ and above. Tests at lower frequencies showed very puzzling discrepancies, which, in a separate investigation, were traced to vibration errors ${ }^{6}$ in the hot-wire instrument. For that reason the results at frequencies less than $1,000 \mathrm{c} / \mathrm{s}$ are not shown in this table.

A plus sign in table 1 indicates that with equal response of the thermal converter on direct and alternating currents the response of the other instrument was greater on alternating than on direct current.

Each thermal converter was compared with the next higher- and lower-range thermal converter in the series at two currents and at selected frequencies from 25 to $20,000 \mathrm{c} / \mathrm{s}$. The results of each of these comparisons at the higher of the two currents at which tests were made are shown in table 2 . They are estimated to be accurate to somewhat better than 0.01 percent, with very little possibility of systematic error. A plus sign in the table indicates that with equal response of the lower-range thermal converter on alternating and on direct currents, the response of the higher-range thermal converter was greater on alternating than on direct currents. This series of tests was made to extend stepwise the results of low-frequency comparisons with the electrodynamic ammeter, and to indicate any highfrequency effects that might well be expected to differ in different thermal converters. ${ }^{7}$ The group

${ }^{6}$ Electromagnetic forces between the hot wire and its closely adjacent iron mounting plate resulted in vibration of the wire because the plate was magnetized mounting plate resulted in vibration of the wire because the plate was magnetized by the damping magnet of the instrument. This vibration caused additional
cooling and thus an error that was as large as 0.2 percent at certain frequencies. 7 The percentage errors due to any high-frequency effects would be expected to be independent of the current level and could thus be evaluated by these tests
TABLE 2. Results of intercomparisons of thermal converters

\begin{tabular}{|c|c|c|c|c|c|c|c|}
\hline \multirow{2}{*}{$\begin{array}{l}\text { Thermal converter } \\
\text { ranges }\end{array}$} & \multirow{2}{*}{$\begin{array}{l}\text { Test } \\
\text { cur- } \\
\text { rent }\end{array}$} & \multicolumn{6}{|c|}{ Comparative ac-dc difference } \\
\hline & & $\begin{array}{l}25 \\
\mathrm{c} / \mathrm{s}\end{array}$ & $\begin{array}{l}100 \\
\mathrm{c} / \mathrm{s}\end{array}$ & $\begin{array}{l}400 \\
\mathrm{c} / \mathrm{s}\end{array}$ & $\begin{array}{c}1,000 \\
\mathrm{c} / \mathrm{s}\end{array}$ & $\begin{array}{c}10,000 \\
\mathrm{c} / \mathrm{s}\end{array}$ & $\begin{array}{c}20,000 \\
\mathrm{c} / \mathrm{s}\end{array}$ \\
\hline & $m a$ & $\%$ & $\%$ & $\%$ & $\%$ & $\%$ & $\%$ \\
\hline 1 to $2 \mathrm{ma}_{--}$ & 1. 2 & 0.000 & & & 0.000 & & +0.006 \\
\hline 2 to $5 \mathrm{ma}$ & 2.4 & +.006 & & & +.003 & & -.003 \\
\hline 5 to $10 \mathrm{ma}_{-.}$ & 6 & +.004 & & & .000 & & .000 \\
\hline 10 to $20 \mathrm{ma}$ & 12 & .000 & & & +.004 & & -.006 \\
\hline 20 to $30 \mathrm{ma}^{a}$ & 24 & +.001 & & -0.003 & -.001 & & .000 \\
\hline $30^{\mathrm{a}}$ to $50 \mathrm{ma}$ & 36 & +.004 & & & .000 & & .000 \\
\hline 50 to $100 \mathrm{ma}$ & 60 & +.024 & +0.028 & & +.036 & & +.027 \\
\hline 100 to $200 \mathrm{ma}_{-.}$ & 100 & -.046 & (....... & & -.044 & -0.050 & -.049 \\
\hline 200 to $500 \mathrm{ma}$ & 240 & +.026 & & & & -..... & +.039 \\
\hline 500 to $1,000 \mathrm{ma}$ & 600 & -.002 & & & -.002 & +.002 & +.002 \\
\hline $1,000 \mathrm{ma}$ to $1 \mathrm{amp}$ & $a m p$ & +034 & & & -065 & -056 & -065 \\
\hline 1 to 2 amp. & 1 & $\begin{array}{l}T .00 t \\
-.028\end{array}$ & -.002 & & $\begin{array}{l}-.000 \\
-.002\end{array}$ & $\begin{array}{r}-.000 \\
-.002\end{array}$ & $\begin{array}{r}-.000 \\
+.001\end{array}$ \\
\hline 2 to $5 \mathrm{amp}$ & 2 & -.123 & -.011 & & +.003 & +.004 & $\begin{array}{r}+.009 \\
+.009\end{array}$ \\
\hline 5 to $10 \mathrm{amp}$ & 5 & -.008 & -.006 & & -.006 & -.007 & -.004 \\
\hline 10 to $20 \mathrm{amp}$ & 10 & -.010 & -.010 & & -.008 & -.012 & -.009 \\
\hline 20 to $50 \mathrm{amp}$ & 20 & -.014 & -.015 & -.014 & -.018 & -.035 & \\
\hline
\end{tabular}

a This 30-ma thermal converter was the one used in the model A voltmeter.

of tests disclosed small discrepancies independent of frequency in a few thermal converters, and verified the absence of any high-frequency errors in the thermal converters tested. However, they could not be used to assign numerical values to the errors of individual thermal converters in the milliampere range as the differences were found to depend upon the current. The concluding series of tests to evaluate these errors were comparisons of a shunted thermal converter with each of those pairs of thermal converters that showed discrepancies in the previous intercomparisons. The model A voltmeter was shunted with a bifilar resistor of computed skin effect and time constant for tests at currents from 1 to 40 amps, and with a suitable high-quality audio-frequency decade resistance box for tests at lower currents. The results are shown in table 3 and are estimated to be accurate to better than 0.01 percent. A positive sign in this table indicates that with equal

TABLE 3. Results of comparisons of selected thermal converters with shunted model A thermal voltmeter

\begin{tabular}{|c|c|c|c|c|}
\hline \multirow{2}{*}{$\begin{array}{l}\text { Thermal converter } \\
\text { range }\end{array}$} & \multirow{2}{*}{$\begin{array}{l}\text { Test } \\
\text { current }\end{array}$} & \multicolumn{3}{|c|}{ Comparative ac-dc difference } \\
\hline & & $25 \mathrm{c} / \mathrm{s}$ & $100 \mathrm{c} / \mathrm{s}$ & $400 \mathrm{c} / \mathrm{s}$ \\
\hline \multirow{2}{*}{$50 \quad m a$} & $m a$ & $\%$ & $\%$ & $\%$ \\
\hline & 60 & -0.003 & & - 100. \\
\hline \multirow[t]{2}{*}{$100 \ldots$} & $\begin{array}{r}70 \\
100\end{array}$ & - & $\begin{array}{r}-0.043 \\
-.062\end{array}$ & - n. \\
\hline & 120 & -.065 & & -0.065 \\
\hline \multirow[t]{2}{*}{200} & 240 & -.010 & +.002 & +.002 \\
\hline & 200 & -.044 & - & -.042 \\
\hline \multirow{2}{*}{500} & 400 & -.056 & (n) & -.054 \\
\hline & $\begin{array}{l}600 \\
400\end{array}$ & $\begin{array}{l}-.068 \\
-.041\end{array}$ & & -.069 \\
\hline \multirow[t]{2}{*}{$1,000 \ldots$} & 600 & $-\ldots$ & -.060 & (n) \\
\hline & 800 & -.061 & -.059 & 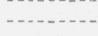 \\
\hline \multirow[t]{8}{*}{$a m p$} & $a m p$ & & & \\
\hline & & -.004 & -..... & -.006 \\
\hline & 10 & -...- & -.014 & -.015 \\
\hline & $\begin{array}{l}12 \\
10\end{array}$ & $\begin{array}{l}-.018 \\
-.003\end{array}$ & (n) & $\begin{array}{l}-.020 \\
-.006\end{array}$ \\
\hline & 20 & -.005 & -.015 & $\begin{array}{l}-.006 \\
-.017\end{array}$ \\
\hline & 24 & -.023 & (n...... & -.024 \\
\hline & 20 & -.008 & $-\ldots-10$ & -.010 \\
\hline & 40 & -.010 & -.010 & -.010 \\
\hline
\end{tabular}


response of the thermal converter on alternating and on direct current the response of the shunted model A voltmeter was greater on alternating than on direct current. The results of tests of the 1-, 2- and 5-amp thermal converters, duplicating those with the electrodynamic ammeter, are not shown in the table. The average difference between eight such duplicate results obtained with this ammeter and with the shunted model A voltmeter was 0.004 percent, and the largest difference was 0.013 percent. A few additional check tests of these thermal converters with the shunted voltmeter were made at other frequencies but are not tabulated.

The results of all these tests were combined to assign reliable values of ac-dc difference, $\delta$, to each thermal converter in the series from 1 ma to $50 \mathrm{amp}$ and to the model A voltmeter. These values were less than 0.01 percent for the model $\mathrm{A}$ voltmeter and for all the thermal converters of ranges less than 100 ma. The values for the other converters (rounded off to the nearest $0.005 \%$ ) are shown in table 4 .

TABLE 4. Observed percentage ac-dc differences of thermal converters (to the nearest 0.005 percent)

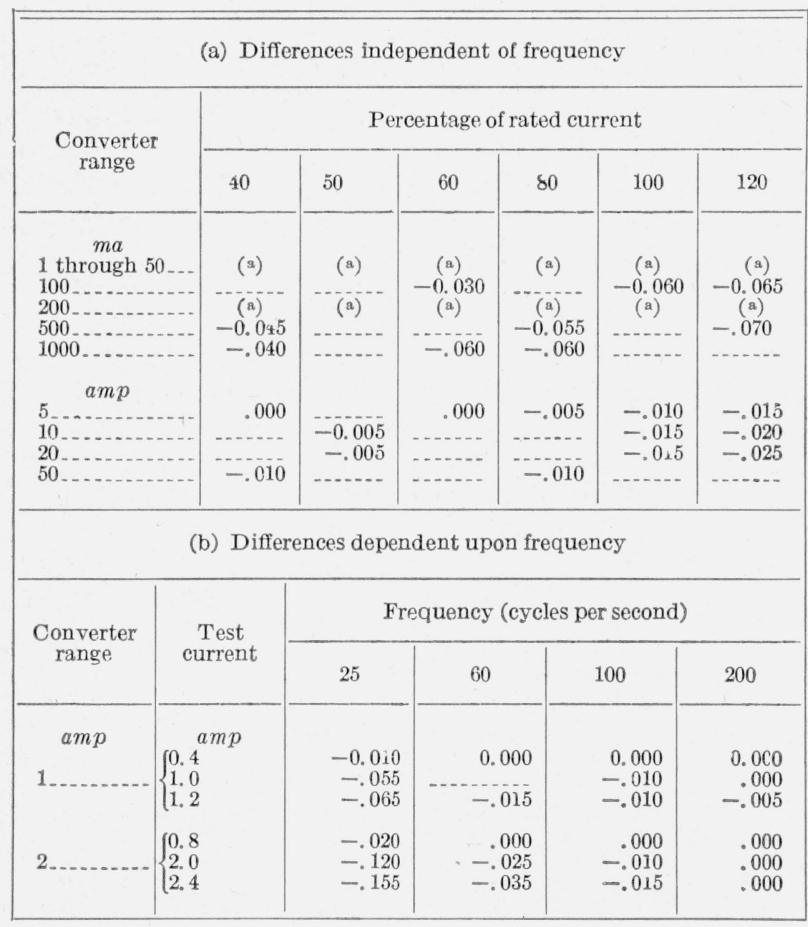

* Less than 0.01 percent throughout.

The model B voltmeter, which was developed to give a wider voltage range and greater convenience of use than the model $A$, was compared with the model A voltmeter at rated voltage on each range up through the $300-\mathrm{v}$ range and at $400 \mathrm{v}$ on the higher ranges, at selected frequencies from 30 to $20,000 \mathrm{c} / \mathrm{s}$. The results are shown in table 5 and represent directly the ac-dc difference, $\delta$, of the model B voltmeter. They disclosed significant but not unexpected errors for the higher voltage ranges at the higher frequencies.
TABLE 5. Results of comparisons of model $A$ and model $B$ thermal voltmeters

\begin{tabular}{|c|c|c|c|c|c|c|}
\hline \multirow{2}{*}{$\begin{array}{l}\text { Range of } \\
\text { model B }\end{array}$} & \multirow{2}{*}{ Voltage } & \multicolumn{5}{|c|}{ ac-dc difference of model B voltmeter } \\
\hline & & $\begin{array}{l}25 \\
\mathrm{c} / \mathrm{s}\end{array}$ & $\begin{array}{c}1,000 \\
\mathrm{c} / \mathrm{s}\end{array}$ & $\begin{array}{c}5,000 \\
\mathrm{c} / \mathrm{s}\end{array}$ & $\begin{array}{c}15,000 \\
\mathrm{c} / \mathrm{s}\end{array}$ & $\begin{array}{c}20,000 \\
\mathrm{c} / \mathrm{s}\end{array}$ \\
\hline $\begin{array}{l}\quad \text { Volts } \\
3 \text { through } 75 \\
150 \\
300 \\
600 \\
750\end{array}$ & $\begin{array}{c}{ }^{v} \\
\text { Rated } \\
400 \\
400 \\
\end{array}$ & $\begin{array}{c}{ }^{\%}{ }^{\%} \\
+0.003\end{array}$ & $\begin{array}{c}\% \\
(\mathrm{a}) \\
+0.011\end{array}$ & $\begin{array}{c}\% \\
(\mathrm{~s}) \\
+0.014 \\
+.028\end{array}$ & $\begin{array}{c}\% \\
\% \\
(\mathrm{a}) \\
-0.044 \\
+0.064 \\
+.04\end{array}$ & $\begin{array}{c}\% \\
(\mathrm{~s}) \\
+0.013 \\
+.021 \\
+.051 \\
+.082\end{array}$ \\
\hline
\end{tabular}

s Less than 0.01 percent, 25 to $20,000 \mathrm{c} / \mathrm{s}$ each range,.

As a result of these extensive series of tests, the transfer performance of each of this first set of thermal converters and of each of the two voltmeters was uniquely determined. Small but significant acdc differences of both known and unsuspected causes were found. Corrections for these differences can readily be applied when these thermal converters are used as transfer standards. However, an investigation of such differences is an especially important objective of a development such as this. As a result of such an investigation, a number of factors that limit the transfer accuracy of an electrothermic instrument were discovered and evaluated, with the results given in the following sections.

\section{D-C Response}

In all measurements with a transfer standard the average of the $d$-c response of the standard for the two directions of current is taken as the reference upon which the a-c measurements are based. For all three types of such standards, the reversed d-c average gives a better basis than does the response for one direction alone as effects that lead to small differences in response for the two directions of direct current are reduced to the second order of smallness when the average is taken.

Reversal differences may be expected in a contact thermal converter because of the flow of heater current through the hot junction of the thermocouple. This can cause a voltage drop in the thermocouple circuit, which may lead to second-order errors because of the nonlinearities of the thermal and electric circuits. This cause of reversal difference is minimized by the special constructions used in most high-range thermal converters, and is eliminated by the use of the small insulating bead between the heater and the thermocouple in the low-range thermal converters. Surprisingly, however, early tests of the first thermal converters purchased for the model A voltmeter showed appreciable reversal differences (up to $0.2 \%$ ) even in these insulated-heater thermal converters. It was soon realized that this was probably due to thermoelectric effects in the heater circuit. Peltier and Thomson heating of the heater can cause dissymmetry in the temperature rise of the heater, and thus cause differences in the emf of the thermocouple unless the hot junction is exactly at the 
midpoint of the heater. ${ }^{8}$ This supposition was verified by an analysis of the data, which showed that the differences were larger in those thermal converters with heaters having larger thermoelectric effects. Further verification was secured by tests of special thermal converters, constructed by one of the manufacturers ${ }^{9}$ at the Bureau's request, with the hot junction of each deliberately and considerably offcenter. The reversal differences were much larger, and the signs and magnitudes were found to be roughly in agreement with calculations based on thermoelectric data for the alloys used.

Early intercomparisons of these few thermal converters indicated that no significant ac-de differences should be expected, even with rather large reversal differences from this cause, provided that the average for the two directions of current is taken as the d-c response. However, intercomparisons and tests of the much larger number of thermal converters later purchased for current measurements showed that a good proportion had measurable ac-dc differences, all of the same sign and independent of frequency. This suggested a d-c error, for which these thermoelectric efforts seemed the most likely cause. This was investigated theoretically (see appendix 2) by considering the temperature rise of a homogeneous conductor heated by an electric current and cooled solely by conduction to two relatively massive terminals; i. e. by neglecting, for simplification, radiation and convection losses and the heat abstracted by the attached thermocouple.

With only the normal joule, or resistance, heating, and with the terminals of the conductor at equal and fixed temperature, the temperature distribution along the conductor is parabolic, and the temperature rise at the midpoint is, as Goodwin showed, ${ }^{10}$ equal to

$$
\theta_{d}=\begin{gathered}
V_{c}^{2} \\
8 \rho k
\end{gathered}
$$

where $V_{c}$ is the voltage drop across the conductor, and $\rho$ and $k$ are the electrical resistivity and thermal conductivity, respectively. In addition, however, there is Peltier heating or cooling at the junctions of dissimilar metals (the two junctions between the heater and its two supports) and Thomson heating along each half of the wire. Unlike joule heating, these are dependent upon the direction of the current flow and can thus cause a dissymmetry of the temperature distribution along the conductor, which reverses when the direct current through the conductor is reversed. On alternating current, even at the low frequencies in which we are interested, the reversal of current occurs so rapidly that the thermal inertia of the wire prevents any such dissymmetry, and the temperature dis-

\footnotetext{
8 This dissymmetry has actually been utilized to measure the Thomson effect. See [9].

M. Rosenfield, of the Field Electrical Instrument Co., who first showed that the reversal differences were dependent upon the type of heater material.

10 See [6]. In addition to this classic paper, Goodwin has written an excellent series of articles on "Thermal problems relating to measuring and control services", which appeared in Weston Eng. Notes, 1948-50 (Weston Electrical Instrument Corp., Newark, N. J.).
}

tribution is unchanged by these thermoelectric effects. Calculations show (see appendix 2) that with direct current the temperature rise at the midpoint of the conductor, where the hot junction of the thermocouple is attached, is unaffected by the Peltier heating, for completely symmetrical construction of a thermoelement. They show, however, that it is changed by Thomson heating, and becomes, approximately, ${ }^{11}$

$$
\theta_{t}=\theta_{d}\left[1-\frac{4}{3}\left(\frac{\sigma \theta_{d}}{V_{c}}\right)^{2}\right]
$$

where $\theta_{t}$ is the midpoint temperature rise in the presence of Thomson heating, in ${ }^{\circ} \mathrm{C}$; $\theta_{d}$, the rise without Thomson heating; $\sigma$, the Thomson voltage coefficient in volts-degree ${ }^{-1}, V_{c}$, the voltage across the conductor in volts.

This was derived by considering $\sigma$ a constant, whereas both experimental results and the electron theory of metallic conduction indicate that $\sigma=B T$, where $B$ is a constant and $T$ is the absolute temperature. However, a solution by a perturbation method, ${ }^{12}$ of the nonlinear equation that results when $\sigma=B T$, shows that the above results give a sufficiently close approximation for the temperature rise of about 200 deg $\mathrm{C}$ encountered in typical thermal converters. Thus eq 2 shows that an ac-de difference, or transfer error, should be expected in a thermal converter, and enables the approximate calculation of this error. Such calculations have been made for some common metals and some of the alloys used as heaters in thermal converters, on the assumption of a $200 \mathrm{deg} \mathrm{C}$ rise at the midpoint, and a voltage drop of $0.2 \mathrm{v}$ at rated currents. ${ }^{13}$ The results, converted to ac-dc difference for the same temperature rise, rather than temperature difference for the same current, are shown in table 6. For the computation of these results, the Thomson coefficient $\sigma$ was considered to be equal to $B\left(\theta_{0}+2 / 3 \theta_{d}+273\right)$, where $B$ is the second derivative of the characteristic curve of emf versus temperature for a thermocouple composed of the indicated metal and lead. ${ }^{14} \quad \theta_{0}$ is the ambient temperature in $\operatorname{deg} \mathrm{C}$. The results show approximately the errors to be expected for these materials.

\begin{tabular}{|c|c|c|}
\hline Metal & B & $\begin{array}{c}a c-d c \\
\text { difference }\end{array}$ \\
\hline $\begin{array}{l}\text { Copper } \\
\text { Platinum } \\
\text { Manganin } \\
\text { Constantan }(60 \mathrm{Cu}-40 \mathrm{Ni}) \\
85 \mathrm{Pt} \text { P } \mathrm{Cr} \text { Ir }\end{array}$ & $\begin{aligned} & v /{ }^{\circ} C^{2} \\
+ & 0.8 \times 10^{-8} \\
- & 3.2 \\
- & 0.08 \\
- & -3.3 \\
- & -2.2 \\
- & 2.1\end{aligned}$ & $\begin{array}{l}\text { Percent } \\
<0.005 \\
=.013 \\
<.005 \\
-.064 \\
-.013 \\
-.005\end{array}$ \\
\hline
\end{tabular}
TABLE 6. Calculated ac-dc difference at rated current due to
Thomson effects in thermal converter heaters

\footnotetext{
11 At other points along the conductor the average temperature rise for the two directions of direct current is also changed by Thomson heating.

12 This method was suggested by Chester Snow.

${ }^{13}$ From eq 1, a series of thermal converters having similar thermocouples and the same rated output emf at rated current, and having heaters that obey the Weidemann-Franz law will all have the same temperature rise and the same voltage drop across the heater. The temperature rise is about $200 \mathrm{deg} C$, and the voltage drop about $0.2 \mathrm{v}$ at rated current for most thermal converters.

14 This weighted average absolute temperature gives results in closer agreement with those computed by the more exact method than does the unweighted average,
} $\theta_{0}+1 / 2 \theta_{d}+273$. 
The results may be compared with the observed ac-dc differences shown in table 4 . From information supplied by the manufacturers, the 1-, 2-, 5-, 10-, 20-, $50-$, and 200-ma thermal converters have heaters of either carbon, nickel-chromium, or platinumrhodium-ruthenium alloys. The observed ac-de differences of these converters were less than 0.01 percent. The 100-, 500- and 1,000-ma thermal converters had heaters of constantan (Advance). The observed differences for these converters (at rated current) were close to the calculated value of -0.06 percent. The 1- and 2-amp converters, of platinumiridium, had observed differences (from table 4,b) less than 0.005 percent, except at low frequencies, also close to the calculated values. The 5-, 10-, 20and 50-amp converters, of a special platinum-3percent-copper alloy, had differences of -0.010 to -0.015 percent. Thus the agreement between the computed and observed values serves as excellent verification of this source of error in transfer thermal converters. Very fortunately, the error is significantly large only for materials having unusually large thermoelectric effects, such as constantan. However, this does lead to the interesting conclusion that for operation at a low temperature a thermal converter should have large thermoelectric effects in the thermocouple, but that for the highest transfer accuracy it should have very small thermoelectric effects in the heater.

Additional experimental verification of this cause of transfer error was secured by constructing ${ }^{15}$ at the Bureau two 5-amp thermal converters differing only in that one had a heater of manganin and the other of constantan. These were 5-amp thermal converters with a small Borax bead between the hot junction of a copper-constantan thermocouple and the center of the heater wire, to eliminate contact effects. Careful ac-dc difference tests with the standard electrodynamic ammeter as the reference established agreement within 0.005 percent for the manganin element and indicated an ac-dc difference of -0.06 percent for the constantan element at an emf of about $5 \mathrm{mv}$.

As a result of this work, a second set of thermal converters in the 1 - to 1,000 -ma range was purchased under specifications prohibiting heaters of constantan or similar alloys. All of these converters were found to have ac-de differences less than 0.01 percent at audio frequencies.

\section{Low-frequency Response}

It has long [10] been known that there is a lowfrequency limit to the correct rms response of a thermal converter, for reasons analogous to those causing a similar low-frequency limit in all other types of transfer instruments. Below this limit the response characteristic $\mathrm{E}=f(\mathrm{I})$ is not independent of frequency (except for symmetrical square waves), and may be expected to be in error by an amount that is inversely proportional to the square of the frequency. As table 4 , b, shows, such an error was observed for the 1 - and 2 -amp thermal converters.

\footnotetext{
15 These thermal converters were constructed by E. S. Williams.
}

When a constant direct current is applied, the heater of a thermal converter reaches a constant temperature. When an alternating current is applied (after the transient state is over) the temperature of the heater varies cyclically about a mean value, with an amplitude that decreases with increasing frequency because of the thermal capacity of the element. At frequencies high enough so that the cyclic variations are negligible, the temperature rise of the heater is independent of frequency (provided that at very high frequencies the skin effect and electromagnetic radiation are negligible and that standing waves do not alter the temperature distribution). However, at lower frequencies the mean value, to which the d-c instrument or potentiometer connected to the thermocouple responds, may not be the same because of nonlinearities in the thermal and electric circuits. These nonlinearities are caused principally by radiation losses, the dependence upon temperature of the electrical resistivity and the thermal conductivity of the heater, and the curvature of the emf versus temperature characteristic of the thermocouple. A theoretical evaluation of these effects for the conditions in a thermal converter, in which most of the cooling is by conduction to the heater, is difficult, but does serve as a guide in determining the approximate limiting frequencies for an arbitrarily chosen error and for determining which factors influence that error. Such an approximate analysis has been carried out by a perturbation method (see appendix 3 ). The results show that the average (time average) temperature rise at the midpoint of a conductor heated by a sinusoidal electric current and cooled solely by conduction to massive terminals is approximately

$$
\theta_{a c}=\theta_{d c}\left[1+\frac{h}{2} \theta_{d c} q^{2}\right]
$$

and that the percentage $a c-d c$ difference of a thermal converter having the hot junction of a thermocouple fastened to the midpoint of such a heater is approximately

where

$$
\delta=-25 H \theta_{d c} q^{2}
$$

$\theta_{a c}=$ the midpoint temperature rise in degrees centigrade on alternating current of rms value $I$ amperes

$\theta_{d c}=$ the midpoint temperature rise in degrees centigrade for the same value of direct current.

$h=\alpha-\beta-2 N T_{0}^{2} l^{2}$, where $\alpha$ is temperature coefficient of electrical resistivity.

$\beta=$ the temperature coefficient of thermal conductivity of the conductor,

$N=p \zeta K / a k$.

$p$ and $a=$ the perimeter and area of the cross section of the conductor, respectively.

$\zeta=$ the emissivity.

$K=$ the Stefan-Boltzmann constant in watts-cm ${ }^{-2}-(\operatorname{deg} K)^{-4}$

$k=$ the thermal conductivity in watts$\mathrm{cm}^{-1}-\mathrm{deg}^{-1}$ 
$T_{0}=$ the ambient temperature in degrees Kelvin

$q=d / \omega l^{2}$ and is (approximately) the ratio of the crest value of the cyclic fluctuation of temperature at the midpoint to the average temperature rise at the midpoint

$\omega=2 \pi f$, where $f$ is the frequency of the applied current in cycles per second.

$d=$ the thermal diffusivity of the heater material in $\mathrm{cm}^{2}-\mathrm{sec}^{-1}$.

$l=$ one-half the length of the conductor in centimeters.

$H=h+B / 2 A$, where $A$ and $B$ are the constants in the emf-temperature characteristic for the thermocouple itself, that is, in the expression, $E=A \theta+(B / 2) \theta^{2}$

These equations indicate the factors upon which the low-frequency error depends. They show that the temperature rise can correctly be used as a measure of the rms alternating current, at frequencies high enough so that the second term in the bracket of eq 3 is negligible for the accuracy desired; in other words, at frequencies for which the heater integrates reasonably well. This is true even if the thermal and electrical conductivities of the heater are dependent upon temperature. As a corollary, these equations show that a thermal converter correctly indicates rms response, except at low frequencies, even though its response characteristic $E=f(I)$ is not quadratic.

The above equations are valid only at frequencies for which the second term in the brackets of eq 3 is small compared to 1 .

Equation 4 may be used to calculate approximately the frequencies for which ac-de differences may be expected to cause an error of an arbitrarily chosen value. This has been done for some typical materials for an error of 0.1 percent, a temperature rise of $200^{\circ} \mathrm{C}$, and a typical heater length of $0.4 \mathrm{~cm}$. The results are shown in table $7 .{ }^{16}$

TABLE 7. Frequencies for which the computed ac-dc difference is 0.1 percent

[TC-A signifies a thermocouple of Chromel P and Alumel, and TC-B a thermocouple of copper and constantan, for which $\mathrm{B} / 2 \mathrm{~A}=-0.1 \times 10^{-3}$ and $+0.9 \times 10^{-3}$, respectively]

\begin{tabular}{|c|c|c|c|c|c|}
\hline \multirow{2}{*}{ Heater material } & \multicolumn{2}{|c|}{$\begin{array}{l}\text { Approximate temperature } \\
\text { coefficient }\end{array}$} & \multirow{2}{*}{$\begin{array}{l}\text { Thermal } \\
\text { diffusivity }\end{array}$} & \multicolumn{2}{|c|}{$\begin{array}{l}\text { Frequency for } \\
\qquad \delta=0.1^{\mathrm{a}}\end{array}$} \\
\hline & $\begin{array}{l}\text { Electrical } \\
\text { resistivity }\end{array}$ & $\begin{array}{c}\text { Thermal } \\
\text { conductivity }\end{array}$ & & $\mathrm{TC}-\mathrm{A}$ & $\mathrm{TC}-\mathrm{B}$ \\
\hline $\begin{array}{l}\text { Copper } \\
\text { Platinum } \\
\text { Manganin } \\
\text { Constantan } \\
80 \mathrm{Ni}-20 \mathrm{Cr} \\
\text { Carbon }\end{array}$ & $\begin{aligned} & \% /{ }^{\circ} \mathrm{C} \\
&+ 3.9 \times 10^{-3} \\
&+ 3.5 \\
&< .1 \\
&<.1 \\
& .1 \\
&-.5\end{aligned}$ & $\begin{array}{l}\quad \% /{ }^{\circ} C \\
-0.2 \times 10^{-3} \\
+.5 \\
+2.7 \\
+2.3 \\
\mathrm{~b}+3.5 \\
+.4\end{array}$ & $\begin{array}{c}\mathrm{cm}^{2}-\mathrm{sec}^{-1} \\
1.1 \\
.25 \\
.075 \\
.064 \\
.038 \\
.2\end{array}$ & $\begin{array}{r}c / s \\
60 \\
12 \\
3 \\
3 \\
2 \\
5\end{array}$ & $\begin{array}{r}c / s \\
70 \\
14 \\
2 \\
2 \\
2 \\
1\end{array}$ \\
\hline
\end{tabular}

a For a heater $0.4 \mathrm{~cm}$ long with a temperature rise of $200^{\circ} \mathrm{C}$.

b Estimated from Lorenz' Law.

16 The effect of radiation losses has been neglected in preparing this table. In general, this effect is significant only in the very low and very high range thermal converters.
It is evident that the most significant factor in the error term of eq 4 is the length of the heater as the error is dependent upon the fourth power of this quantity. ${ }^{17} \mathrm{It}$ is of interest to note that the lengths, $2 l$, of the heater of the 1 - and 2-amp thermal converters are only 0.28 and $0.19 \mathrm{~cm}$, respectively, and that the length of each of the higher-range thermal converters is about $0.5 \mathrm{~cm}$. The value of $H$ can be determined from the departure from "square law" of the characteristic equation $E=f(I)$ of a thermal converter. For these thermal converters it was considerably less than the factor given for platinum in table 7 . The estimated frequencies for a 0.1-percent error, on the assumption that the diffusivity of the platinum-iridium alloy used in these thermal converters is the same as that of platinum, were about one-half the observed values.

\section{High-Frequency Response}

As these thermal converters are inherently suitable at frequencies up to $100 \mathrm{Mc}$ or more, the upperfrequency limit is set by the circuits in which they are used. The precautions indicated in section 4 are sufficient to control capacitance and leakage currents in tests of ammeters at frequencies considerably higher than the $20,000 \mathrm{c} / \mathrm{s}$ established as the present upper limit by the demand for this testing service. The actual upper-frequency limit has not been established.

The magnitude of the effective impedance sets the upper frequency limit for the model $\mathrm{A}$ and the model $B$ voltmeters. For an accuracy of 0.01 percent at $20,000 \mathrm{c} / \mathrm{s}$, a time constant of less than $1 \times 10^{-7}$ and a skin effect less than 0.01 percent are necessary for the impedance of each step of the model $A$ and each range of the model $B$ instruments. The time constant of each decade of the model A voltmeter was computed from the inductance and direct-capacitance values furnished by the manufacturer of the resistance box used. This was less than $5 \times 10^{-8}$ for each decade. The skin effect was also negligible for each decade. The resistance box is connected as a three-terminal resistor, with the shield connected to the grounded side of the line. For this connection the errors caused by the capacitance currents to the shield are much less than those that would occur if the shield were connected to a resistor terminal. They are significant only for the two 1,000-ohmsper-step decades. The effects of the capacitance of the resistance cards and switch studs of these decades to the shield were computed from the manufacturer's capacitance figures of about $10 \mu \mu \mathrm{f}$ per decade by considering the capacitance as distributed along a uniform transmission line, composed of resistance elements and short-circuited at the end. From the usual transmission line formulas, the magnitude of

17 For a given heater alloy, the low-frequency range can be extended by using longer heaters, with proportionately greater cross-sectional area to give the same temperature rise for the same current. If solid heaters are used, the improved temperature rise for the same current. If solid heaters are used, the improved
low-frequency performance will be accompanied by increased error due to skin effect at high frequencies. 
the current at the short-circuited end was computed as approximately

$$
|I|=\frac{V}{R}\left[1-0.0056(\omega C R)^{2}\right],
$$

where

$V=$ the applied voltage

$I=$ the current at the short-circuited end

$R=$ the resistance in the circuit

$C=$ the total capacitance to shield of the $\omega=2 \pi f$. windings in use

At $20,000 \mathrm{c} / \mathrm{s}$ for a capacitance of $30 \mu \mu \mathrm{f}$ this is changed by less than 0.005 percent at 20,000 ohms, the maximum setting. The effect of the capacitance (about $10 \mu \mu \mathrm{f}$ ) of each rather large switch blade to the shield was separately computed, and found to be less than 0.005 percent at $20,000 \mathrm{c} / \mathrm{s}$. Thus it was concluded that the errors of this voltmeter should be a maximum of 0.01 percent at the highest settings and frequencies used, and less at lower settings and frequencies. The performance at the top settings was verified by the tests outlined in section 4 .

The impedance of the model B voltmeter was similarly computed, and only the capacitance to the shield was found to be significant. As a rough but adequate approximation this may be considered the same for each step, which leads to the approximation of considering the capacitance as distributed along a nonuniform transmission line composed of resistance elements and short-circuited at the end. The effective impedance was computed by a perturbation method, ${ }^{18}$ on the rough assumption that the resistance per unit length was proportional to the square of the electrical distance from the output end. The magnitude of the current at the short-circuited end was found to be approximately

$$
|I|=\frac{V}{R}\left[1-0.0022(\omega C R)^{2}\right] .
$$

From the measured capacitance of $50 \mu \mu \mathrm{f}$ and the total resistance of $100,000 \mathrm{ohms}$ for the $750-v$ range, the change in current was computed as -0.09 percent at $20,000 \mathrm{c} / \mathrm{s}$, which is in very good agreement with the observed results of table 5. Moderately good agreement for the other ranges was also obtained, but the change in current was not observed to increase in proportion to the square of the frequency as indicated by eq 6 . However, the agreement is good enough to show that the ac-dc difference of this instrument is due to capacitance currents to the shield. These currents cannot easily be reduced in a shielded multirange instrument of reasonable size. (A shield is desirable to control the currents.) They could be compensated by connecting appropriate capacitors across sections of the resistors, but this seems less desirable than the procedure of applying: small corrections and has not been done in the model B voltmeter. Much of the capacitance is that between the binding posts of each range (see fig. 2)

\footnotetext{
18 See appendix"4.
}

and between the high-side binding post and the top shield. This shield is brought as close as $2.5 \mathrm{~cm}$ to the row of high-side posts.

\section{Other Effects}

The intercomparisons of insulated-heater thermal converters disclosed an unsuspected ac-dc difference that was dependent upon the voltage between the heater and ground and upon the heater current of each of these elements. This was traced to a very small leakage current flowing through the ceramic bead between the heater and thermocouple and then through the stray capacitance of the Lindeck potentiometer to ground. This current caused additional heating of the bead and thus an error as on direct current the insulation resistance of the Lindeck was much higher than the capacitive reactance, even at $20 \mathrm{c} / \mathrm{s}$. In addition, the ceramic bead of each of these thermal converters exhibited marked dielectric absorption, so that its a-c resistance was much less than its d-c resistance. For a typical thermal converter at rated current a leakage current of $0.7=\mu$ a resulted from a difference of $50 \mathrm{v}$ between the heater and ground, resulting in a power dissipation of $35 \mu \mathrm{W}$ in the bead. This was sufficient to cause a 0.2-percent error, which was proportional to the square of the voltage difference and was very markedly dependent upon the heater current. ${ }^{19}$ The reactance of a capacitance as small as $100 \mu \mu \mathrm{f}$ is less than the computed bead resistance, even at a frequency as low as $50 \mathrm{c} / \mathrm{s}$, so that in almost any application this source of error makes it necessary to maintain the heater near ground potential.

\section{Other Applications}

This equipment was designed for the testing of other instruments. Portability and the ease of making other a-c measurements were not considered to be important. However, the thermal converters and voltmeter elements are readily portable and have been used, with a small portable millivolt potentiometer as the indicator, for measurements at other locations. For measurements of current or voltage to 0.01 percent, it is necessary to use a transfer method, calibrating the thermal converter or voltmeter on direct current at the time of use. For a more moderate accuracy of about 0.1 percent, it should be feasible to use a low-range thermal converter, shunting it for current measurements and adding a series resistor for voltage measurements. Only the thermal converter itself need be transferred to direct current if the resistances of the shunts and the series resistor are properly adjusted. Thus d-c sources of extended range, volt boxes, etc., should be unnecessary. The whole apparatus could be built in a convenient case, containing a small potentiometer for the measurements of the current through. or the voltage across the thermal converter heater.

19 This was due to the marked decrease in the resistance of the ceramic bead with an increase in temperature. With a fixed voltage across the bead, the error was in some cases proportional to the tenth power of the heater current. 
A suitable low-range thermal converter should also make feasible an a-c potentiometer with an inherent accuracy of 0.01 percent. The basic circuit for a polar form of such a potentiometer (to measure the magnitude but not the components or phase angle of an alternating voltage) is shown in figure 6 . With the switch thrown to direct-current the potentiometer is standardized in the usual manner, and the deflection of the indicator of the thermal converter is observed. The switch is then thrown to alternating current, which is adjusted for the same deflection of this indicator. The circuit is surely not new, but a proved thermal converter makes possible a convenient transfer with accuracies comparable to those of a d-c potentiometer. The other basic limitation remains that any a-c potentiometer measures only the fundamental component of the unknown voltage. However for an alternating quantity having a harmonic content as large as 2 percent, the rms value differs from the fundamental by only 0.02 percent. Audio-frequency oscillators and amplifiers with amplitude distortion much less than this are now available. Such an oscillator could be used to supply the potentiometer directly and to supply the test circuit through an amplifier preceded by a suitable phaseshift network.

\section{Summary}

The electrothermic transfer standards used at the Bureau for the precise measurement of voltage and current at audio frequencies, and designed primarily for the standardization of electric instruments, have been described. The extensive tests to establish the transfer performance of the standards have been outlined, and the results have been given. The causes of the observed ac-dc differences have been outlined and the errors evaluated. The equations governing the temperature rise of a conductor heated by an electric current and cooled by conduction to relatively massive terminals have been solved to establish the steady-state midpoint temperature rise on direct current with Peltier and Thomson heating, as well as the ordinary resistance heating, in order to obtain the $d$-c error of a thermal converter. The equations have been solved to establish the average midpoint temperature rise on alternating current, in order to obtain the low-frequency error of a thermal converter in which the electrical and thermal conductivities of the heater are temperature dependent, in which some loss of heat occurs by radiation, and in which the characteristic of the thermocouple is nonlinear. Possible applications and modifications of the equipment for measurements under less stringent conditions have been suggested, and the application to an a-c potentiometer of excellent inherent accuracy has been diagrammed.

The results of this work establish the excellence of thermal converters as transfer standards of highest accuracy, comparable over wide ranges with that obtainable with other types of standards at much narrower ranges. The requirements for such standards are feasible and the manner of use to insure such accuracy not unreasonable. The cost of the required number of standards and the equipment is not prohibitive. Thus electrothermic instruments may be ranked on a par with electrodynamic and electrostatic instruments for a-c measurements of the highest accuracy.

As a result of this work, thermal converters of negligible or small known transfer error are now available as transfer standards with which the transfer performance of other thermal converters may be evaluated at the NBS to 0.01 percent at audio frequencies.

The autbor acknowledges the help of Murray Blitz, who made most of the intercomparisons described in section 4 of this report and checked all the tables and equations, and of Earl Williams, who constructed all the equipment and assisted with the measurements.

\section{References}

[1] F. K. Harris, A suppressed-zero electrodynamic voltmeter, BS J. Research 3, 445 (1929) RP105.

[2] J. H. Park and A. B. Lewis, Standard electrodynamic wattmeter and ac-dc transfer instrument, J. Research NBS 25, 545 (1940) RP1344.

[3] F. B. Silsbee, Composite-coil electrodynamic instruments, BS J. Research 8, 217 (1932) RP411.

[4] C. C. Patterson, E. H. Rayner, and A. Kinnes, The use of the electrostatic method for the measurement of power, J. Inst. Elec. Engrs. (London) 51, 294 (1913).

[5] R. S. J. Spilsbury and A. Felton, The electrostatic voltmeter as a dc-ac transfer instrument, J. Inst. Elec. Engrs. (London) 89-II, 129 (1942).

[6] W. N. Goodwin, Jr., The compensated thermocouple ammeter, Trans. Am. Inst. Elec. Engrs. 55, 23-33 (1936)

[7] F. L. Hermach, A precision electrothermic voltmeter for measurements between 20 and 20,000 cycles, Trans. Am. Inst. Elec. Engrs. 67, 1224 (1948).

[8] H. B. Brooks and A. W. Spinks, A multi-range potentiometer and its application to the measurement of small temperature differences, BS J. Research 9, 781 (1932) RP506.

[9] G. Borelius, Bestimmung des Thomsoneffektes aus dem thermischen Gleichgewicht in einem strömdurchflossenen Drahte, Ann. Physik 63, 845 (1920).

[10] M. G. Lloyd, Elec. Rev. \& Western Elec. 58, 65 (Jan. 14, 1911).

\section{Appendix 1. Development of Working Equations}

By definition, the percentage ac-de difference of an instrument is the percentage difference in the quantity required to give the same response on alternating and direct current. It is

$$
\delta=100 \frac{Q_{a c}-Q_{d c}}{Q_{d c}},
$$

where $\mathrm{Q}$ is the quantity (current, voltage, or power) that the instrument measures.

In a "straight a-c test" the direct current or voltage is adjusted to give the same response of the transfer standard observed on alternating current. The direct current or voltage is measured with the potentiometer and its accessories. Therefore, from the above definition,

$$
Q_{a c}=Q_{d c}\left(1+\frac{\delta_{s}}{100}\right)
$$


where $Q_{d c}$ is the quantity measured with the potentiometer, $\delta_{s}$ is the ac-de difference of the transfer standard, and $\mathrm{Q}_{a c}$ is the a-c value required for the observed deflection of the test instrument.

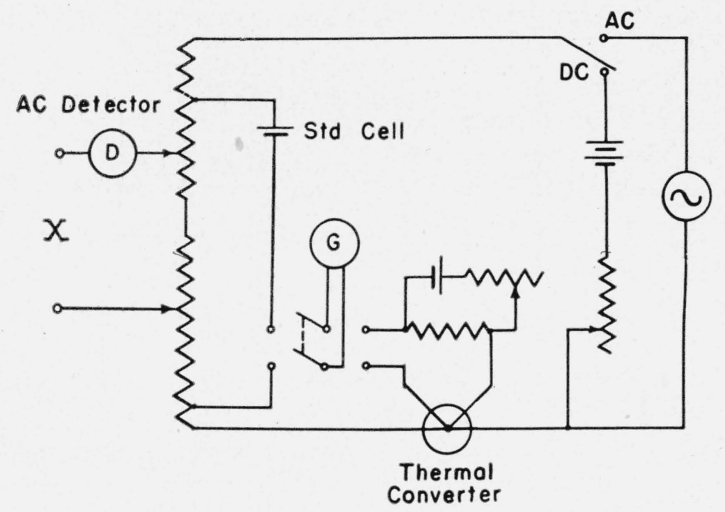

Figure 6. Elementary form of Polar a-c potentiometer.

When a thermal converter is used for transfer tests the small percentage difference, $\delta_{t}$, between the values required for the same indication of the test instrument on alternating and direct current is determined from the resulting deflection of the Lindeck galvanometer. Therefore, for each transfer thermal converter, the small percentage difference in output emf resulting from a small percentage difference in heater current must be evaluated. This relationship may be expressed as

$$
\frac{\Delta E}{E}=n \frac{\Delta I}{I},
$$

where $E$ is the output voltage, $I$ the heater current, and $n$ a number that is generally close to 2 , but may range from from 1.5 to 2.2 . The characteristic, $n$, may be evaluated on direct current by measuring with a potentiometer the small percentage differences in $\mathrm{E}$ resulting from small percentage differences in heater current successively set with a potentiometer at selected current levels, then computing $n$ by the above expression and plotting $n$ versus $E$. The characteristic need not be determined with an accuracy better than 1 percent and is relatively permanent.

If the Lindeck potentiometer shown in figure 3 is used to measure $E$ and $\Delta E$ in millivolts in a transfer test, then at balance $E=V_{p},{ }^{20}$ the voltage drop across the four-terminal resistor. If the galvanometer deflection $D$, is directly proportional to the current through the galvanometer ${ }^{21}$ and if the potentiometer voltage is unchanged during a determination,

$$
\Delta E=\frac{\Delta D R_{p}}{S},
$$

where $\Delta D$ is the difference in galvanometer deflection corresponding to a difference $\Delta E$ in the applied emf, $R_{p}$ is the resistance of the galvanometer circuit, and $S$ is the current sensitivity of the galvanometer in centimeters per milliampere on the scale. In the Lindeck potentiometer used in this setup, the galvanometer sensitivity is adjusted so that numerically

$$
\frac{100 R_{p}}{S}=1
$$

These relationships may be combined with eq 9 to give

$$
100 \frac{\Delta I}{I}=\frac{\Delta D}{n V_{p}}
$$

20 An accuracy of 1 percent is sufficient for this measurement.

21 The use of a straight instead of cylindrical scale introduces an error that can be shown to be less than 1 percent if the galvanometer-to-scale distance is at least three times the scale length.
Therefore, for a transfer test of an ammeter with a thermal converter that has no transfer error, the required ac-dc difference of the test instrument is by eq 7 and 10

$$
\delta_{T}=100\left(\frac{I_{a c}-I_{d c}}{I_{d c}}\right)=\frac{D_{a c}-D_{d c}}{n V_{p}},
$$

where the alternating and direct currents are adjusted for the same response of the test instrument, and the resulting galvanometer deflections are $\mathrm{D}_{a c}$ and $\mathrm{D}_{d c}$, respectively.

If the transfer thermal converter has a percentage ac-dc difference, $\delta_{s}$, at the current and frequency at which the test is made, then the ac-de difference of the instrument under test is, to the desired order of approximation,

$$
\delta_{T}=100\left(\frac{I_{a c}-I_{d c}}{I_{d c}}\right)=\frac{D_{a c}-D_{d c}}{n V_{p}}+\delta_{s} .
$$

Similarly, for a voltmeter test,

$$
\delta_{T}=100\left(\frac{V_{a c}-V_{d c}}{V_{d c}}\right)=\frac{D_{a c}-D_{d c}}{n V_{p}}+\delta_{s},
$$

in which $\delta_{s}$ is the percentage ac-de difference of the range (or setting) of the standard voltmeter used.

In this deflection method of using the Lindeck potentiometer for rapid transfer tests, the resistance of the circuit seen by the galvanometer must be constant to better than 1 percent. The resistance of the thermocouple of each thermal converter has been adjusted to the same value so that the simplified formulas may always be used. The temperature coefficient of the resistance of the Lindeck circuit has been computed as less than 0.1 percent per deg C, and computations show that the resistance seen by the galvanometer is changed by less than 0.2 percent by the adjustable battery circuit, for all ranges of the potentiometer except the topmost.

\section{Appendix 2. Effect of Peltier and Thomson Heating}

The problem is to find the steady-state temperature rise of a uniform conductor of length $2 l$ and uniform cross-sectional area, $a$, carrying a constant current, $I$, and cooled solely by conduction to its terminals. The joule heating of a length $d x$ occurs at the time rate $I^{2} \rho d x / a$ watts, where $\rho$ is the electric resistivity in ohm-cm. The difference in the heat conducted per second across the two ends of this differential element is $a k\left(d^{2} \theta / d x^{2}\right) d x$ watts where $k$ is the thermal conductivity in watts-cm ${ }^{-1}$-degrees ${ }^{-1}$, and $\theta$ is the temperature of the element in deg C. Equating these and dividing by $d x$ gives the differential equation governing the temperature of the conductor

$$
a k \frac{d^{2} \theta}{d x^{2}}+\frac{I^{2} \rho}{a}=0
$$

which is of the form

$$
\theta^{\prime \prime}=-b \text {, }
$$

where $b=I^{2} \rho / a^{2} k$.

If the terminals remain at equal temperatures $\theta_{0}$, and if the origin is at the midpoint of the conductor, the boundary conditions are $\theta=\theta_{0}$ at $x= \pm l$. The solution, by direct integration and application of these conditions, is

$$
\theta-\theta_{0}=\frac{b}{2}\left(l^{2}-x^{2}\right)
$$

and at the midpoint

$$
\theta_{m}-\theta_{0}=\frac{b l^{2}}{2}=\theta_{d}
$$

If the terminals are of different metal than the conductor Peltier heating and cooling (proportional to the first power of the current) mav occur at the junctions of the conductor with the terminals. These will be equal and opposite in sign at the two terminals, and, if we can assume complete thermal symmetry, their effect will be to raise the tempertaure of 
one terminal by a small amount $\Delta \theta$ and to lower the other by an equal amount. The differential equation then has as its boundary conditions, $\theta=\theta_{0}+\Delta \theta$ at $x=+l$ and $\theta=\theta_{0}-\Delta \theta$ at $x=-l$. The solution is

$$
\theta-\theta_{0}=\frac{b}{2}\left(l^{2}-x^{2}\right)+\frac{\Delta \theta x}{l},
$$

and is therefore unchanged at the midpoint. ${ }^{22}$ Of course, complete thermal symmetry is never attained, so that Peltier heats may cause a change in the midpoint temperature. However, for massive terminals the temperature changes, $\Delta \theta$, are very small, so that Peltier heating need not be considered significant.

Thomson heating occurs in homogeneous conductors having a temperature gradient in the direction of the current flow. For the one-dimensional case here considered, the Thomson heat in an element of length $d x$ having a temperature difference $d y$ is $\sigma I d \theta$ watts where $\sigma$ is the Thomson voltage coefficient. Experiment and theory indicate that $\sigma$ is proportional to the absolute temperature, but, as the Thomson heating is small compared to the joule heating, we might, as a first approximation, consider $\sigma$ constant. Equation 14 then becomes

$$
a k \frac{d^{2} \theta}{d x^{2}}+\frac{I^{2} \rho}{a}+\sigma I \frac{d \theta}{d x}=0
$$

which is of the form

$$
\theta^{\prime \prime}+c \theta^{\prime}+b=0
$$

with the boundary conditions $\theta=\theta_{0}$ at $x= \pm l$, where $c=\sigma I / a k$. The steady-state solution of this eq is

$$
\theta-\theta_{0}=\frac{\mathrm{b} l}{c}\left(\frac{1}{\tanh q}-\frac{e^{-c x}}{\sinh q}\right)-\frac{b x}{c}
$$

where $q=c l<<1$. At the midpoint, where $x=0$

$$
\theta_{m}-\theta_{o}=\frac{b l^{2}}{q}\left(\frac{\cosh q-1}{\sinh q}\right) .
$$

Expanding the hyperbolic functions gives, by neglecting higher-order terms,

$$
\theta_{m}-\theta_{0}=\theta_{t}=\frac{b l^{2}}{2}\left(1-\frac{q^{2}}{12}\right)=\theta_{d}\left(1-\frac{q^{2}}{12}\right) .
$$

By substituting the values for $b$ and $c$ and noting that $2 I \rho l / a=V$, the voitage drop across the conductor, eq 1 and 2 of the text can be obtained. They show that Thomson heating causes a small (second order of smallness) decrease in the temperature rise at the midpoint of the conductor, and can thus lead to a transfer error in a thermal converter. However, the approximation of considering $\sigma$ a constant is a drastic one, and a more accurate approach will be to consider $\sigma=B T$, where $B$ is a constant, ${ }^{23}$ and $T$ is the absolute temperature. Equation 17 then becomes

$$
a k \frac{d^{2} T}{d x^{2}}+\frac{I^{2} \rho}{a}+B I T \frac{d T}{d x}=0
$$

which is of the form

$$
T^{\prime \prime}+w T T^{\prime \prime}+b=0,
$$

with the boundary conditions $T=T_{0}$ at $x= \pm l$, where $w=B I / a k$

This is a nonlinear equation and very difficult to solve. Chester Snow showed that it could be reduced to a Ricatti and then to a Bessel equation, but suggested an approximation or perturbation method to give the desired results more simply and directly. The answer is not significantly different from

22 Since Peltier heating depends upon the junction temperature, a secondorder change in midpoint temperature may occur.

order change in midpoint temperature may occur. question and a metal such as lead, which has very small Thomson heating. that of eq 18. The method is powerful, however, and was used later in evaluating other perturbing effects, so that it will be outlined here. The Thomson heating, which is much smaller than the Joule heating, can be considered as perturbing the temperature distribution of the conductor. Its effect can be approximated by solving the differential equation without the perturbing term, then substituting the result, and its derivatives as necessary, in the perturbing term only, and solving the resulting equation.

Without the Thomson heat term, eq 19 becomes

$$
T^{\prime \prime}=-b
$$

with the boundary condition given, the solution of which is

$$
T_{1}-T_{0}=\frac{b}{2}\left(l^{2}-x^{2}\right)
$$

where the subscript 1 indicates the first approximation. Placing this value of $T_{1}$ and $T_{1}^{\prime}$ in the perturbing term of 19 , reduces this to a linear equation,

$$
T_{2}^{\prime \prime}=-b-\frac{w b^{2} x^{3}}{2}+w b x\left(T_{d}+T_{0}\right)
$$

where $T_{d}=b l^{2} / 2$, the solution of which is

$$
\begin{aligned}
T_{2}-T_{0}= & \frac{b}{2}\left(l^{2}-x^{2}\right)-\frac{w b^{2} x^{5}}{40}+\frac{w b}{6}\left(T_{d}+T_{0}\right) x^{3}- \\
& w T_{d}\left(\frac{7}{30} T_{d}+\frac{T_{0}}{3}\right) x
\end{aligned}
$$

At $x=0$ this reduces to $T_{1}-T_{0}$ as only first-order terms are given, so that the process must be repeated to find the secondorder term indicated by eq 18 . The algebra rapidly becomes very lengthy and tedious, but the procedure is straightforward, and the resulting temperature rise at the midpoint is found to be approximately

$T_{3}-T_{0}=T_{d}\left[1-3.4 \times 10^{-2} z_{d}^{2}-10.5 \times 10^{-2} z_{0} z_{d}-8.3 \times 10^{-2} z_{0}^{2}\right]$,

where $z_{0}=w T_{0} l$, and $z_{d}=w T_{d} l$

\section{Appendix 3. Low-Frequency Error of a Thermoelement}

The problem is to find the steady-state average (over an integral number of cycles) temperature rise at the center of a uniform conductor of length, $2 l$, and cross-sectional area, $a$, carrying a sinusoidal current and cooled chiefly by conduction to massive terminals that are at fixed and equal temperatures. Assume that the current remains sinusoidal and that only Joule heating of the conductor occurs. If all the cooling is by conduction to the terminals, the differential equation governing the temperature of the conductor is, under these assumptions,

$$
a k \frac{\partial^{2} \theta}{\partial x^{2}}+\frac{i^{2} \rho}{a}=a m s \frac{\partial \theta}{\partial t}
$$

with the boundary condition $\theta( \pm l, t)=0$, where $\theta=$ temperature in $\operatorname{deg} \mathrm{C}$

$i^{2}=$ the square of the instantaneous value of the current $=$ $I^{2}(1-\cos 2 \omega t)$

$I=$ rms value of the current

$\omega=2 \pi f$, and $f$ is the frequency of the current in cycles per second

$t=$ time in seconds

$m=$ density of the conductor in grams- $\mathrm{cm}^{-3}$

$s=$ thermal capacity of the conductor in joules-grams ${ }^{-1}$ $-\operatorname{deg} \mathrm{C}^{-1}$ 
The procedure will be to consider $\rho$ and $k$ constant and to solve for the periodic steady-state temperature rise, then to approximate $\rho$ and $k$ as $\rho=\rho_{0}(1+\alpha \theta)$ and $k=k_{0}(1+\beta \theta)$, to introduce radiation loss, and to solve the resulting equation by the perturbation method just outlined. For the cases considered $\alpha \theta$ and $\beta \theta$ are considerably less than 1 , and radiation loss is much less than the Joule heating of the conductor.

With $\alpha$ and $\beta=0$, eq 21 is the form

$$
\frac{\partial^{2} \theta}{\partial x^{2}}-g \frac{\partial \theta}{\partial t}=-b(1-\cos 2 \omega t)
$$

where $g=m s / k_{0}$, and $b=I^{2} \rho_{0} / a^{2} k_{0}$.

Let $\theta=u(x, t)+\psi(x)$. Then

$$
\frac{\partial^{2} \theta}{\partial x^{2}}=\frac{\partial^{2} u}{\partial x^{2}}+\frac{\partial^{2} \psi}{\partial x^{2}}
$$

Let $\partial^{2} \psi / \partial x^{2}=-b . \quad$ Then $\psi=-\left(b x^{2}\right) / 2+c_{1} x+c_{2}$. Applying boundary conditions gives

$$
\begin{gathered}
\theta(+l, t)=u(+l, t)+\psi(l)=0 \\
\theta(-l, t)=u(-l, t)+\psi(-l)=0 .
\end{gathered}
$$

We may take $\psi(l)=\psi(-l)=0$.

Then $\psi=b / 2\left(l^{2}-x^{2}\right)$ and eq 22 becomes

$$
\frac{\partial^{2} u}{\partial x^{2}}-g \frac{\partial u}{\partial t}=b \cos 2 \omega t
$$

with $u( \pm l, t)=0$

From complex number theory if $u$ is harmonic in time, it can be represented by the real part of $U e^{j 2 \omega t}$, where $U$ is a complex function of the real variable $x$, and $j=\sqrt{-1}$. Similarly, $b \cos 2 \omega t$ can be represented by the real part of $b e^{j 2 \omega t}$, where $b$ is a real number. Substituitng these quantities and the appropriate derivatives in eq 23 and dividing by $e^{i 2 \omega t}$ results in

$$
\frac{d^{2} U}{d x^{2}}-j 2 \omega g U=b
$$

with $\mathrm{U}=\mathrm{O}$ when $x= \pm l$. The solution of this is

$$
U=-\frac{b}{\mu_{2}}\left[1-\frac{\cosh \mu x}{\cosh \mu l}\right]
$$

where $\mu=\sqrt{j 2 \omega g}$. At the midpoint

$$
U=-\frac{b}{\mu^{2}}\left[1-\frac{1}{\cosh \mu l}\right] \approx j \frac{b}{2 \omega g}
$$

as at the frequencies we are interested in $\cosh \mu l>>1$. Therefore, $u=$ real part of $U e^{i 2 \omega t}=$ real part of

$$
\left\{\frac{j b}{2 \omega g}(\cos 2 \omega t+j \sin 2 \omega t)\right\} \approx-\frac{b}{2 \omega g} \sin 2 \omega t .
$$

So that, to this approximation, at the midpoint

$$
\theta_{m 1}=\frac{b l^{2}}{2}\left(1-\frac{1}{\omega g l^{2}} \sin 2 \omega t\right)=\theta_{d}(1-q \sin 2 \omega t),
$$

where $\theta_{d}=b l^{2} / 2$ and $q=1 / \omega g l^{2}$. Note that $q$ is the crest value of the cyclic temperature fluctuation divided by the average temperature rise at midpoint.

In general, $U=U_{a}+j U_{b}$, where $U_{a}$ and $U_{b}$ are functions of $x$, so that $u=U_{a} \cos 2 \omega t-U_{b} \sin 2 \omega t$ and

$$
\theta_{1}=\frac{b}{2}\left(l^{2}-x^{2}\right)+U_{a} \cos 2 \omega t-U_{b} \sin 2 \omega t .
$$

Thus the average value over an integral number of cycles of the temperature rise is the same as that found in appendix 2 for the same numerical value of direct current, so that under these conditions the temperature rise of the conductor can be used as a measure of the current without ac-dc error.

We shall now consider that $\rho=\rho_{0}(1+a \theta)$ and $k=k_{0}(1+\beta \theta)$ and that some small fraction of the total heat is lost by radiation. If $p$ is the perimeter of the heater in centimeters, then the heat radiated per second from the surface of a differential length, $d_{x}$, of the heater is

$$
d H_{r}=p \xi K\left(T^{4}-T_{0}^{4}\right) d x,
$$

where $\zeta$ is the emissivity of the heater material, a numerical constant, and $K$ is the Stefan-Boltzmann constant in watts$\mathrm{cm}^{-2}(\operatorname{deg} K)^{-4}$. $\quad T$ is the absolute temperature of the element; $T_{0}$ is the absolute temperature of the surroundings. Introducing these terms in eq 22 gives, as $\beta \theta<1$,

$$
\frac{\partial^{2} \theta}{\partial x^{2}}-g(1-\beta \theta) \frac{\partial \theta}{\partial t}=-b(1-\cos 2 \omega t)(1+\eta \theta)+\frac{p \zeta K}{a k}\left(T^{4}-T_{0}^{4}\right)
$$

where $\eta=\alpha-\beta$. The perturbing terms are

$$
\begin{gathered}
+\beta g \theta \frac{\partial \theta}{\partial t} \\
-b(1-\cos 2 \omega t) \eta \theta \\
\frac{p \zeta K}{a k}\left(T^{4}-T_{0}^{4}\right) .
\end{gathered}
$$

As these perturbing terms are relatively small, the solution will differ by only a small amount from that given by eq 27 . Hence a sufficient expression for these small terms will be given by substituting the known values of the dependent variables $y$ from eq 27 , and its derivatives as necessary, in these perturbing terms. When this is done, it is found that the first of these terms reduces to functions of $x$, each multiplied by $\sin n \omega t$ or $\cos n \omega t$, where $n=2,4$. The second reduces to similar harmonic terms plus the terms $-b[\eta P-$ $\left.\left(\eta U_{a} / 2\right)\right]$, where $P=\left(l^{2}-x^{2}\right) b / 2$. The third term becomes unnecessarily complex. It can be simplified by making the further approximation that for this term

and

$$
T-T_{0}=\theta_{r}=P(1-q \sin 2 \omega t),
$$

$$
T^{4}-T_{0}^{4}=\left(T_{0}+\theta_{r}\right)^{4}-T_{0}^{4} \approx 4 \theta_{r} T_{0}^{3}+6 \theta_{r}^{2} T_{0}^{2}, \theta_{r}<T_{0}
$$

and also that $k=k_{0}$. With these approximations, this term reduces to harmonic terms plus the terms

$$
4 N T_{0}^{3} P+6 N T_{0}^{2} P^{2}\left(1+\frac{q^{2}}{2}\right)
$$

where $N=p \zeta K / a k_{0}$.

Thus eq 28 becomes

$$
\begin{aligned}
\frac{\partial^{2} \theta}{\partial x^{2}}-g \frac{\partial \theta}{\partial t}= & -b\left(1+\eta P-\frac{\eta U_{a}}{2}\right)+2 N T_{0}^{2} P\left[2 T_{0}+3 P 1+\left(\frac{q^{2}}{2}\right)\right]+ \\
& \sum_{n=2}^{n=4}\left(F_{n} \cos n \omega t+G_{n} \sin n \omega t\right),
\end{aligned}
$$

where $F_{n}$ and $G_{n}$ are known functions of $x$ alone. We again let $\theta(x, t)=u(x, t)+\psi(x)$ and set $\partial^{2} \psi / \partial x^{2}$ equal to the terms independent of $t$ in eq 29 , so that

$$
\frac{\partial^{2} u}{\partial x^{2}}-g \frac{\partial u}{\partial t}=\sum_{n=2}^{n=4}\left(F_{n} \cos n \omega t+G_{n} \sin n \omega t\right)
$$


For each frequency of the harmonic driving terms in the right-hand side of this equation, the solution of the equation that vanishes at the end points will be of the form $U_{a} \cos$ $n \omega t-U_{b}$ sin $n \omega t$, where $U_{a}$ and $U_{b}$ are functions of $x$. The average value, over an integral number of cycles of the lowest frequency, will therefore vanish. Since this is a linear equation, the solution is the sum of such solutions and will therefore also vanish. Thus the average value of $\theta$, which we are interested in, is equal to $\psi(x)$.

Evaluation $\psi(x)$ in the same manner as before gives for the value of $\psi$ at the midpoint where $x=0$,

$$
\psi(0)=\theta_{d}\left[1+\frac{5}{6} \eta \theta_{d}-\frac{\eta U_{a 2}(l)}{l^{2}}-\frac{5}{3} N T_{0}^{3} l^{2}-\frac{11}{5} N T_{0}^{2} \theta_{d} l^{2}\left(1+\frac{q^{2}}{2}\right)\right]
$$

where

$$
U_{a 2}(x)=\int_{0}^{x} d x_{2} \int_{0}^{x_{2}} U_{a}\left(x_{1}\right) d x_{1}
$$

and on the assumptions that $U_{a 2}(-l)=U_{a 2}(l)$ and $U_{a 2}(0)=0$.

The required expression for $U_{a}$ can be evaluated from eq 25 and 27 by noting that

$$
\mu x=\sqrt{j 2 \omega g} x=\gamma x+j \gamma x \text { and } \mu l=\mu l+j \gamma l,
$$

where $\gamma=\sqrt{\omega g}$, so that $\cosh \mu x=\cosh \gamma x \cos \gamma x+j \sinh \gamma x \sin$ $\gamma x$, and $\cosh \mu l=\cosh \gamma l \cos \gamma l+j \sinh \gamma l \sin \gamma l$. At the frequencies we are interested in $\mu l>5$, so that

$$
\cosh \mu l \approx \frac{e^{\gamma l}}{2}(\cos \gamma l+j \sin \gamma l) \text {. }
$$

Since $u=$ real part of

$U e^{j \omega t}=r e\left\{\frac{j b}{2 \omega g}\left[1-\frac{\cosh \mu x}{\cosh \mu l}\right] e^{j 2 \omega t}\right\}=U_{a} \cos 2 \omega t-U_{b} \sin 2 \omega t$, it will be found that

$$
U_{a}=\frac{b}{\omega g e^{\gamma l}}[\sinh \gamma x \sin \gamma x \cos \gamma l-\cosh \gamma x \cos \gamma x \sin \gamma l] .
$$

Performing the desired integration results in

$U_{\boldsymbol{a} 2}=-\frac{b}{2 \omega g \gamma^{2} e^{\gamma l}}(\cos \gamma l \cosh \gamma x \cos \gamma x+\sin \gamma l \sinh \gamma x \sin \gamma x)$.

From which

$$
U_{a 2}(l)=U_{a 2}(-l) \approx-\frac{b}{4 \omega^{2} g^{2}} \text { and } U_{a 2}(0)<<U_{a 2}(l) .
$$

Therefore, eq 31 becomes

$$
\begin{aligned}
\psi(0)=\theta_{a c}=\theta_{d}\left[1+M+\left(\frac{\eta}{2}-\frac{11}{10} N T_{0}^{2} l^{2}\right) \theta_{d} q^{2}\right]= \\
\theta_{d}\left[1+M+\frac{h}{2} \theta_{d} q^{2}\right],
\end{aligned}
$$

where $M$ is equal to the remaining terms in eq 31 and $h \approx \eta-$ $2 N T_{0}^{2} l^{2}$.

By the same procedure, eq 28 can be solved for the d-c case by considering $\partial \theta / \partial t=0$ and $i=I$, a constant of the same numerical value as the rms value of the alternating current. .The temperature rise at the midpoint will be found to be

$$
\theta_{a c}=\theta_{d}[1+M] \text {. }
$$

Thus the temperature rise on direct current is the same as on alternating current when the frequency is high enough so that the third term in the brackets of eq 32 is sufficiently small compared to unity. Therefore the temperature rise at the midpoint on alternating current is

$$
\theta_{a c}=\theta_{d c}\left[1+\frac{h \theta_{d c} q^{2}}{2(1+M)}\right] \approx \theta_{d c}\left[1+\frac{h}{2} \theta_{d c} q^{2}\right]
$$

if $M$ is small compared to unity.
If the hot junction of the thermocouple is fastened to the midpoint of the heater, the emf of the couple may be represented by

$$
E=A \theta_{m}+\frac{B}{2} \theta_{m}^{2}
$$

where $\theta_{m}$ is the temperature of the hot junction in $\operatorname{deg} \mathrm{C}$, and $A$ and $B$ are constants to be evaluated at the temperature of the cold junction. On direct current $\theta_{m}=\theta_{d c}$ and

$$
E=A \theta_{d c}\left[1+\frac{B}{2 A} \theta_{d c}\right]
$$

On alternating current of the same rms value, $\theta_{m}$ may be considered to be closely enough for these purposes

$$
\theta_{m}=\theta_{d c}\left[1+\frac{h}{2} \theta_{d c} q^{2}\right](1-q \sin 2 \omega t) .
$$

The average value of emf over an integral number of cycles of alternating current is then (to the desired accuracy, and if $(B / 2 A) \theta_{d c}$ is small compared to unity)

$$
E_{A}=A \theta_{d c}\left(1+\frac{B}{2 A} \theta_{d c}\right)\left[1+\left(\frac{h}{2}+\frac{B}{4 A}\right) \theta_{d c} q^{2}\right]
$$

From these expressions

where $H=h+B / 2 A$.

$$
\frac{E_{a}-E_{d}}{E_{d}}=\frac{H}{2} \theta_{d c} q^{2}
$$

For table 7, it is desired to compute the frequency at which the ac-de difference of a thermal converter due to this effect is equal to 0.1 percent. From eq 7 and 9 and for $n=2$ the difference in current for the same emf is one-half the difference in emf for the same current, and is opposite in sign. Therefore the percentage ac-de difference, $\delta$, is approximately

$$
\delta=-25 H \theta_{d c} q^{2}=\frac{-25 H \theta_{d c} d^{2}}{(2 \pi f)^{2} l^{4}}
$$

where in addition to the symbols already defined, $d=1 / g=$ $k_{0} / m s$ and is the thermal diffusivity in appropriate units.

\section{Appendix 4. Effect of Shield Capacitance on the Model B Voltmeter}

We may approximate the effects' of capacitance to the shield of this voltmeter by considering the voltmeter as consisting of a transmission line of $r_{x}=r_{0} x^{2}$ ohms per unit length, having a constant capacitance $c_{0}$ farads per unit length to the shield, witha sinusoidal voltage of rms value $V$ volts applied to the high-resistance end. The other end may be considered short-circuited, since the thermal converter, which is connected between the low-resistance end and the ground post, is of low resistance. The shield is also connected to this ground post. We wish to find the magnitude of current, $I_{0}$, at the short-circuited end. For an element of length $d x$ at a distance $x$ from this end, we have

$$
\frac{d V}{d x}=I r_{x}=I r_{0} x^{2} \text { and } \frac{d I}{d x}=j \omega c_{0} V,
$$

where $d V$ is the rms voltage drop across the element, and $d I$ is the rms current from the element to the shield. Differentiating the first of these and substituting the values of $I$ and $d I / d x$ in the resulting expression gives

$$
\frac{d^{2} V}{d x^{2}}-\frac{2}{x} \frac{d V}{d x}-\lambda^{2} x^{2} V=0,
$$

subject to the boundary conditions $V=0$ at $x=0$ and $V=V_{a}$ at $x=l$ and where $\lambda^{2}=j \omega c_{0} r_{0}$.

When $\lambda=0$ this becomes, with the same boundary conditions,

$$
\frac{d^{2} V}{d x^{2}}-\frac{2}{x} \frac{d V}{d x}=0
$$


the solution of which is

$$
V_{1}=\frac{V_{a} x^{3}}{l^{3}}
$$

We now put this value of $T$ in the perturbing term containing $\lambda^{2}$ in eq 36 , to get

$$
\frac{d^{2} V}{d x^{2}}-\frac{2}{x} \frac{d V}{d x}=\frac{\lambda^{2} V_{a} x^{5}}{l^{3}}
$$

The solution of this, with the same boundary conditions, is

$$
V_{2}=\frac{V_{a} x^{3}}{l^{3}}\left(1-\frac{\lambda^{2} l^{4}}{28}\right)+\frac{\lambda^{2} V_{a} x^{7}}{28 l^{3}}
$$

As $\lambda^{2}=j \omega c_{0} r_{0}$, we will need to repeat this process to secure terms in $\lambda^{4}$, for we are interested in the magnitudes of $V$ and $I$. Putting the above value of $V_{2}$ in the last term of eq 36 and solving as before gives

$V_{3}=\frac{V_{a} x^{3}}{l^{3}}\left(1-\frac{\lambda^{2} l^{4}}{28}+8.8 \times 10^{-4} \lambda^{2} l^{4}\right)+\frac{\lambda^{2} V_{a} x^{7}}{28 l^{3}}\left(1-\frac{\lambda^{2} l^{4}}{28}\right)+\frac{\lambda^{4} V_{a} x^{11}}{2464 l^{3}}$
From eq 35

$$
I=\frac{1}{r_{0} x^{2}} \frac{d V}{d x} .
$$

Performing the indicated differentiation of eq 37 and substituting in 38 , and noting that the total resistance is $R=r_{0} l^{3} / 3$ leads to

$$
I=\frac{V_{a}}{R}\left[1-\frac{\lambda^{2} l^{4}}{28}+8.8 \times 10^{-4} \lambda^{2 l^{4}}+\frac{\lambda^{2} x^{4}}{12}\left(1-\frac{\lambda^{2} l^{4}}{28}\right)+\frac{\lambda^{4} x^{8}}{672}\right] .
$$

Solving for $I_{0}$ at $x=0$, and noting that the total capacitance is $C=c_{0} l$ gives

$$
J_{0}=\frac{V_{a}}{R}\left[1-j 0.107 \omega C R-7.9 \times 10^{-3}(\omega C R)^{2}\right] .
$$

Since the terms in the bracket are small compared with unity

$$
\left|I_{0}\right|=\frac{V_{a}}{R}\left[1-0.0022(\omega C R)^{2}\right] .
$$

Washington, August 16, 1951. 